\title{
Visible-light-mediated synthesis of amides from aldehydes and amines via in-situ acid chloride formation
}

\author{
Naeem Iqbal ${ }^{\mathrm{a}}$ and Eun Jin Cho*,b \\ a Department of Chemistry and Applied Chemistry, Hanyang University, Ansan, 426-791, \\ Republic of Korea \\ bDepartment of Chemistry, Chung-Ang University, Seoul 156-756, Republic of Korea \\ [Phone: (82)-2-820-5946, E-mail: ejcho@cau.ac.kr].
}

\section{Supporting Information}

\section{Content}

General Considerations 


\section{General Considerations}

\section{General Reagent Information}

Anhydrous acetonitrile $\left(\mathrm{CH}_{3} \mathrm{CN}\right)$ in Sure-Seal bottles was purchased and degassed by repeated sonication under light vacuum and replenishing the atmosphere with argon. All reagents unless otherwise prepared, including $\left[\mathrm{Ru}(\mathrm{bpy})_{3}\right] \mathrm{Cl}_{2} \cdot 6 \mathrm{H}_{2} \mathrm{O}$ were purchased from commercial suppliers and used as received. Flash column chromatography was performed using silica gel 60 (70-230 mesh).

\section{General Analytical Information}

NMR spectra of products were recorded on a $300 \mathrm{MHz}$ (for ${ }^{1} \mathrm{H} \mathrm{NMR}$ ) or $600 \mathrm{MHz}$ instrument (600 MHz for ${ }^{1} \mathrm{H}$ NMR and $151 \mathrm{MHz}$ for ${ }^{13} \mathrm{C}$ NMR). Copies of ${ }^{1} \mathrm{H}$ and ${ }^{13} \mathrm{C}$ NMR spectra can be found at the end of the Supporting Information. ${ }^{1} \mathrm{H}$ NMR data are reported in $\delta$ units, parts per million (ppm), and referenced relative to residual chloroform (7.26 ppm) or DMSO (2.50 ppm) in the deuterated solvent. ${ }^{13} \mathrm{C}$ NMR spectra are reported in ppm relative to deuteron chloroform (77.23 ppm) or DMSO-D 6 (39.51 ppm). Coupling constants were reported in Hz. 


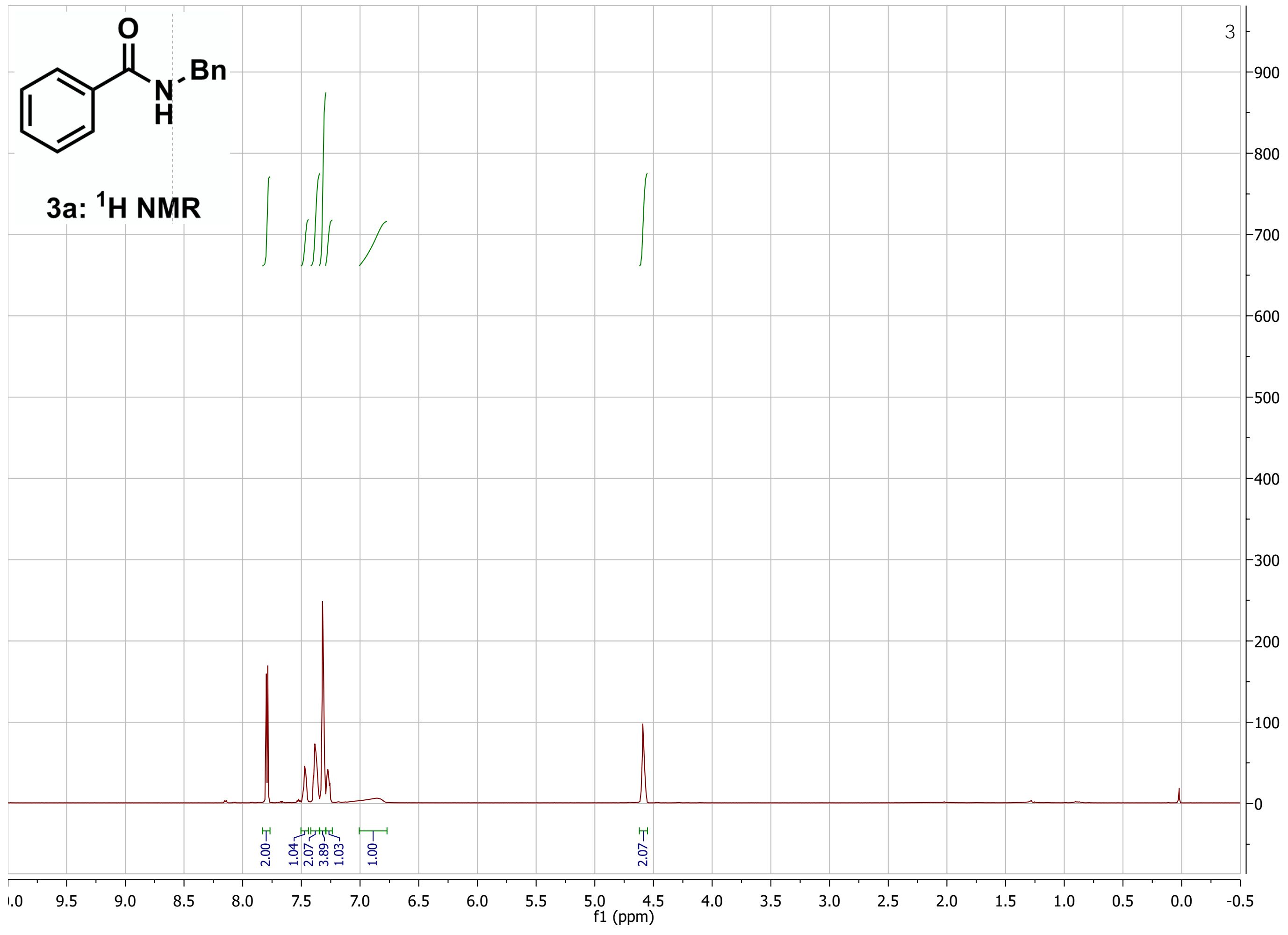




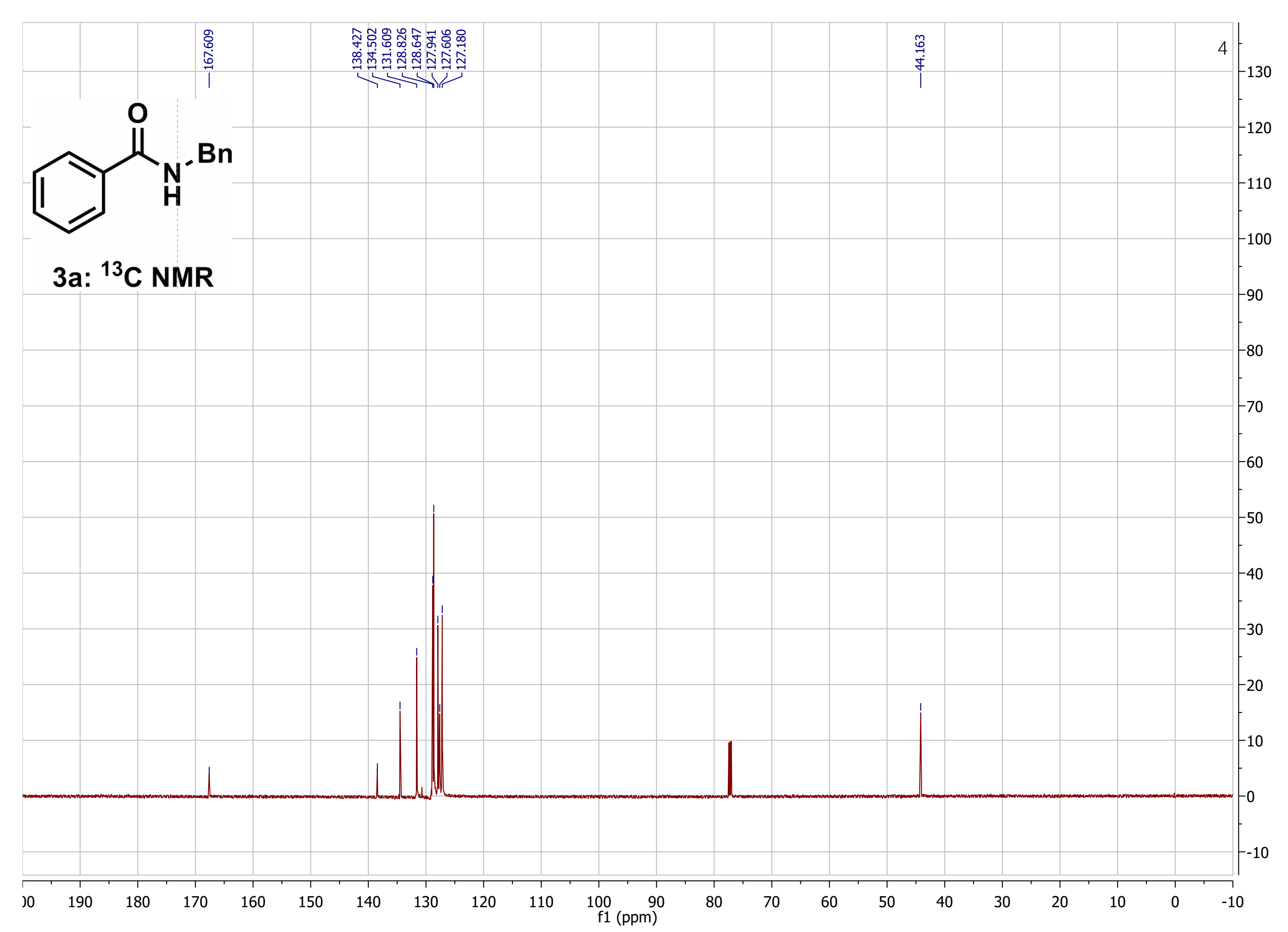




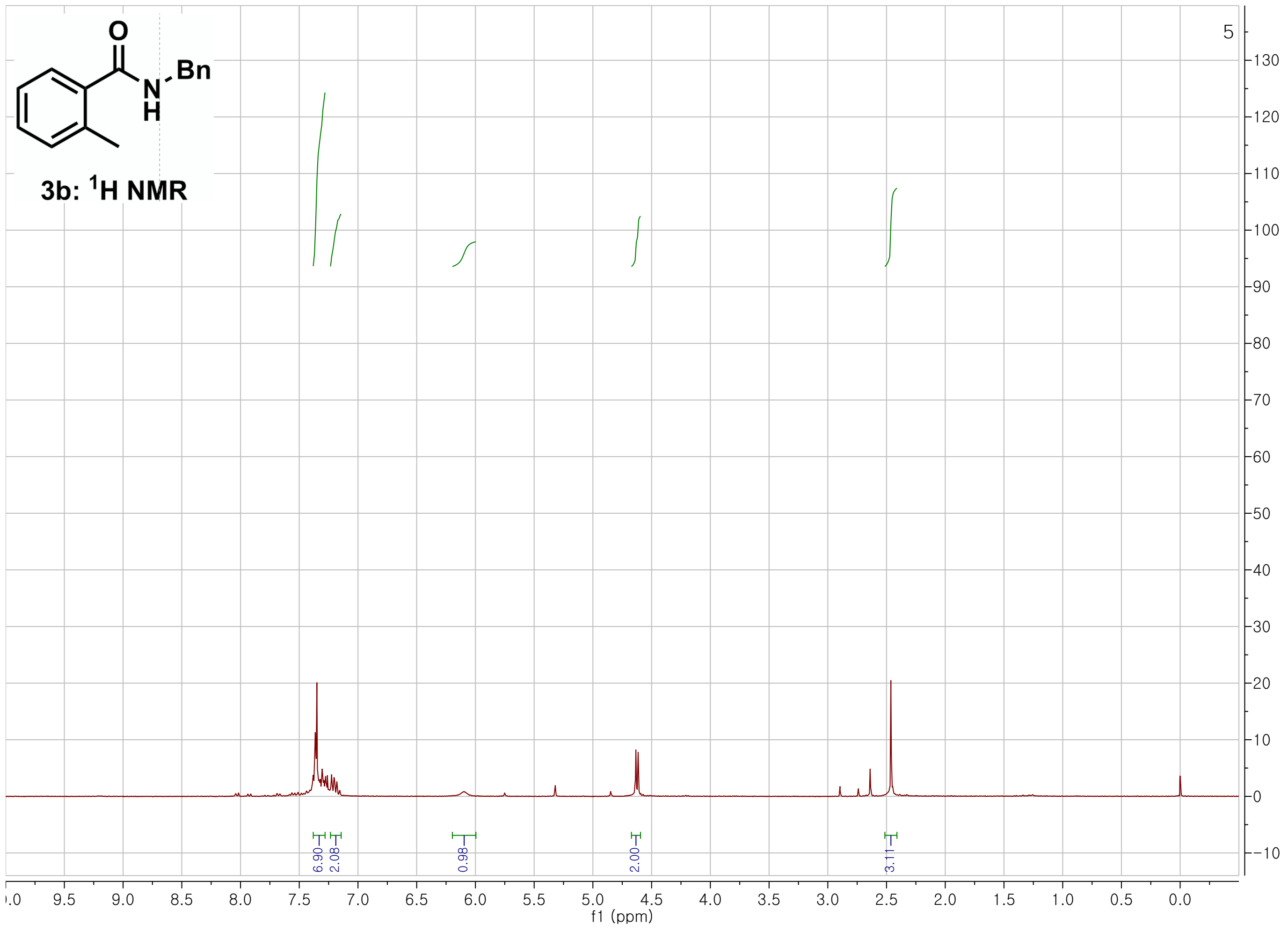




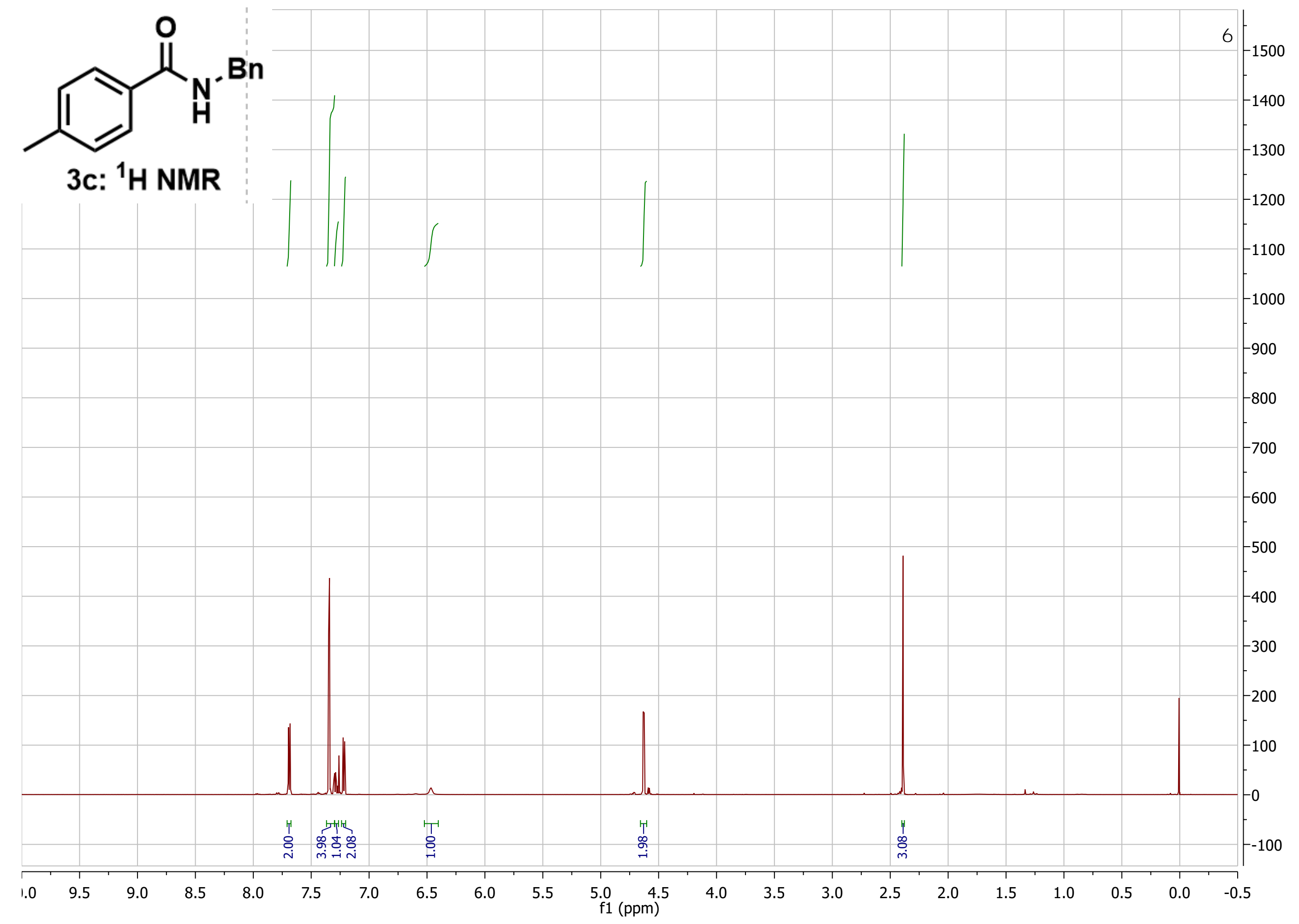




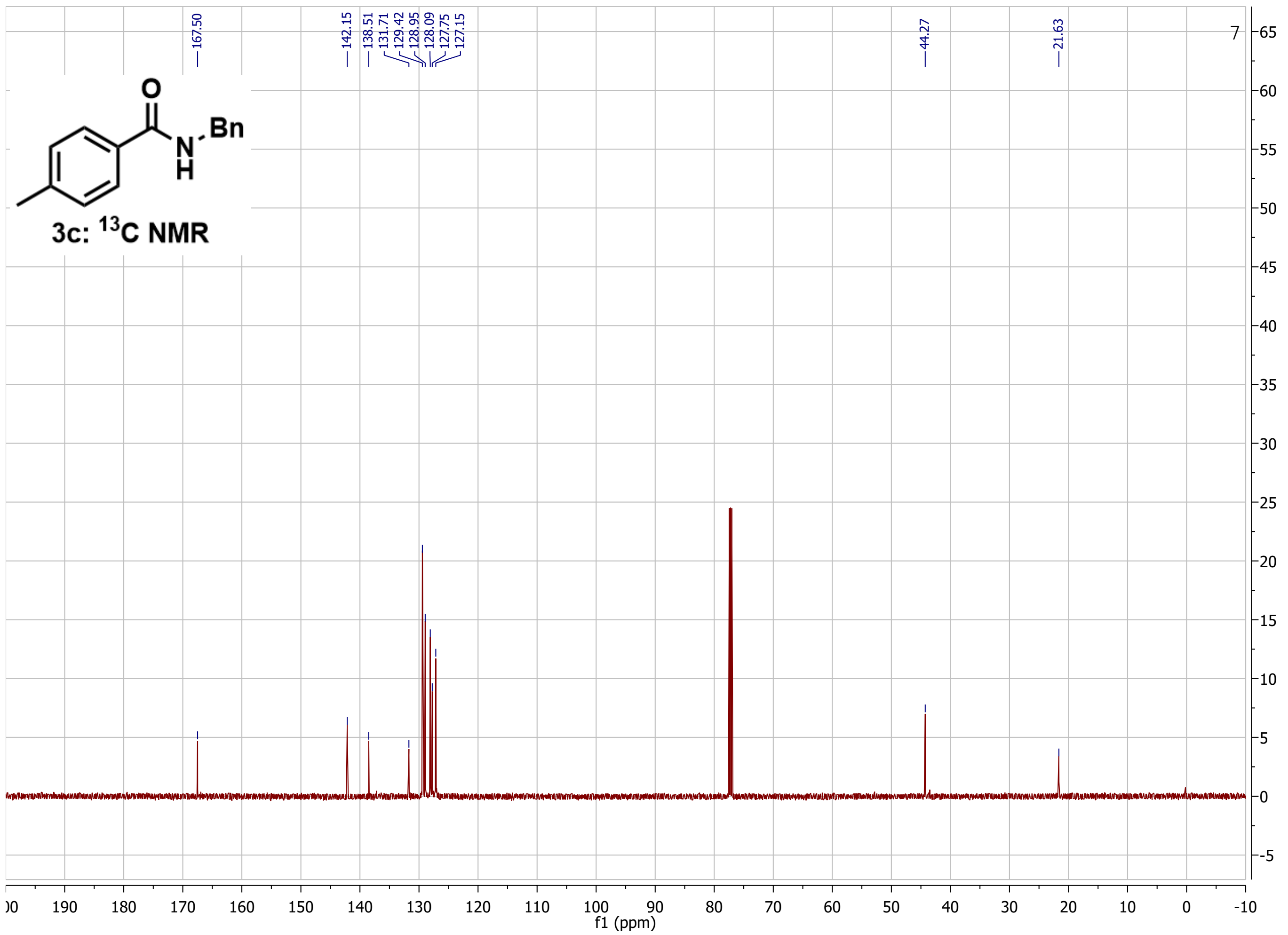




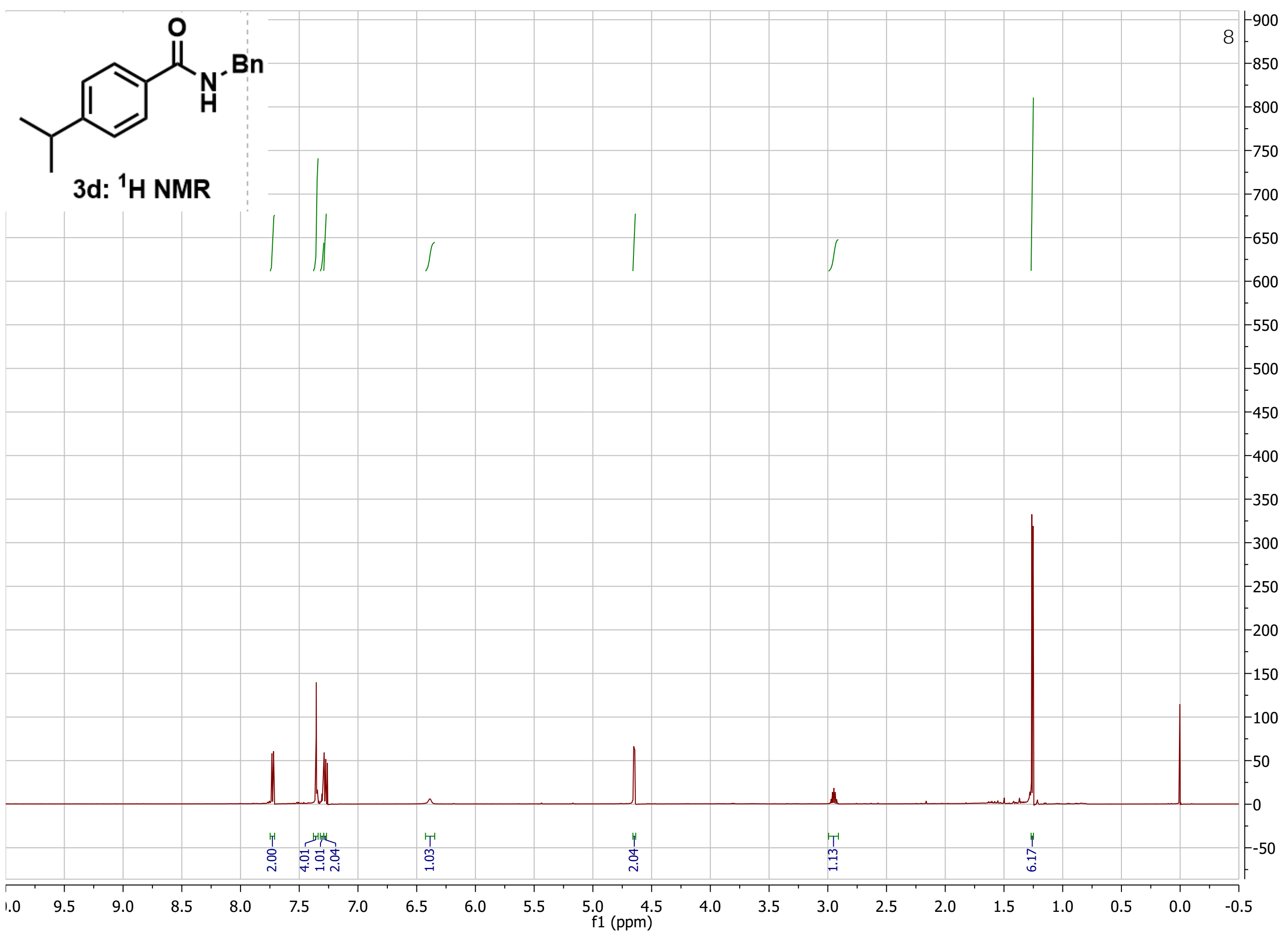




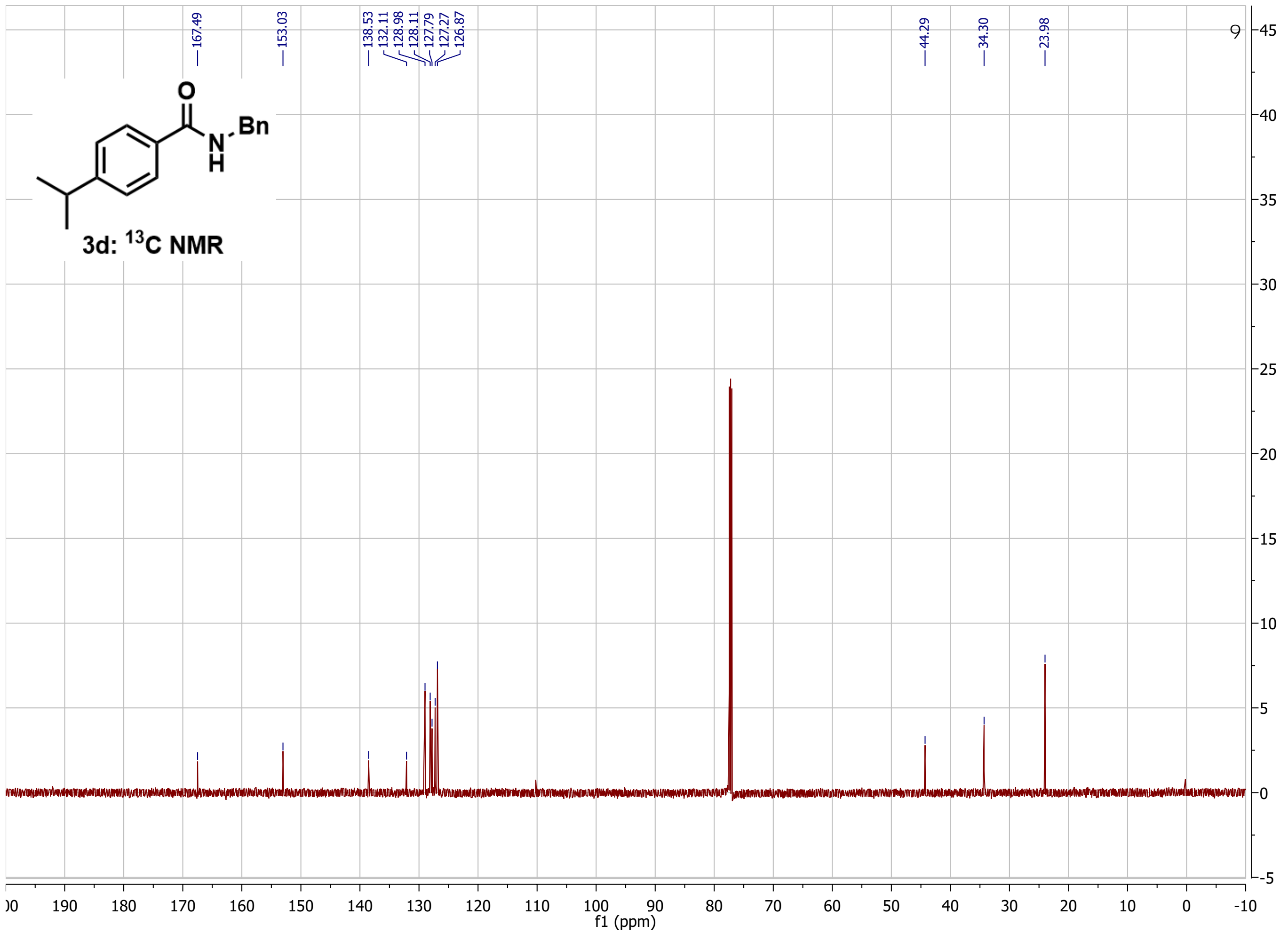




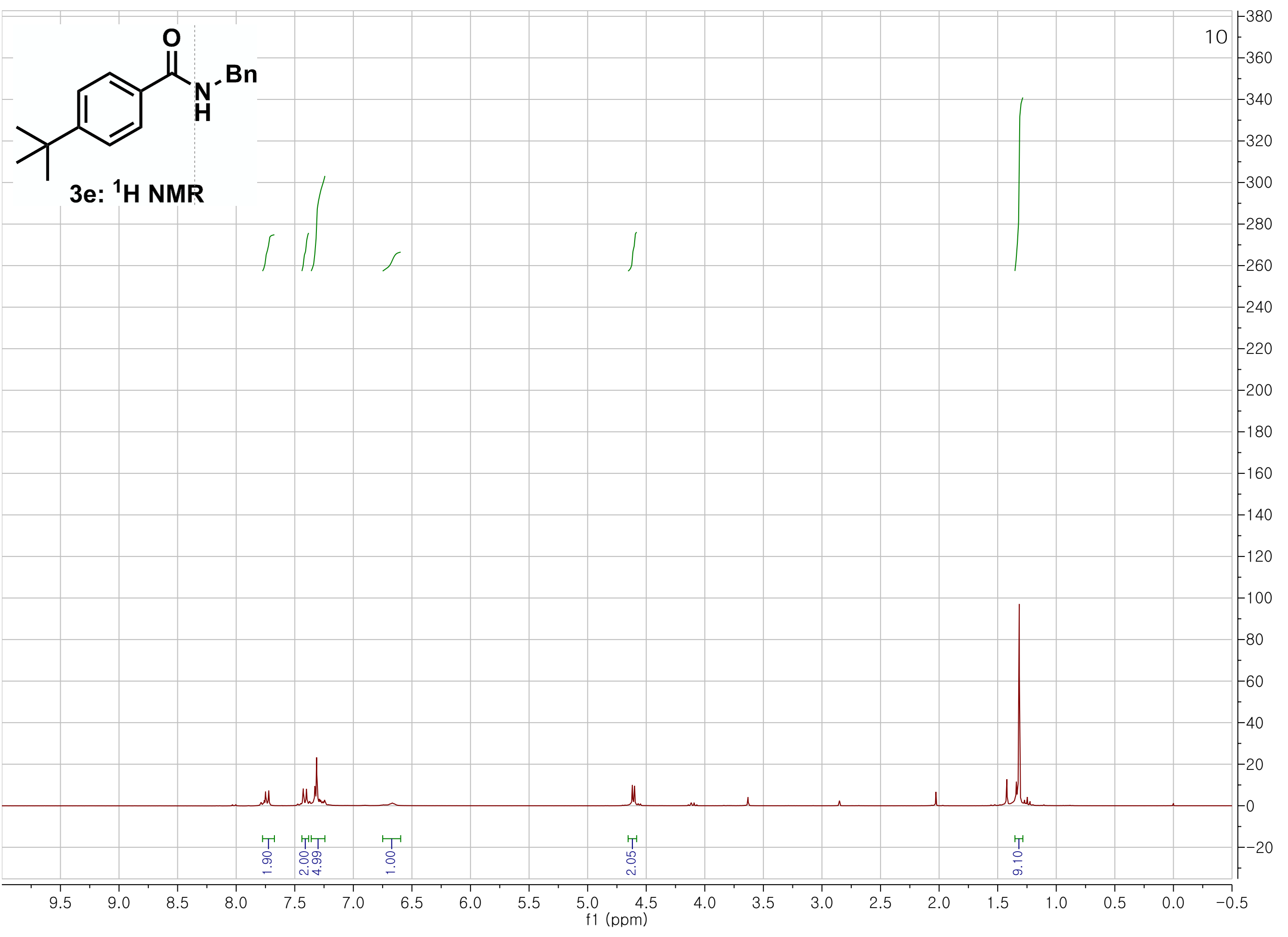




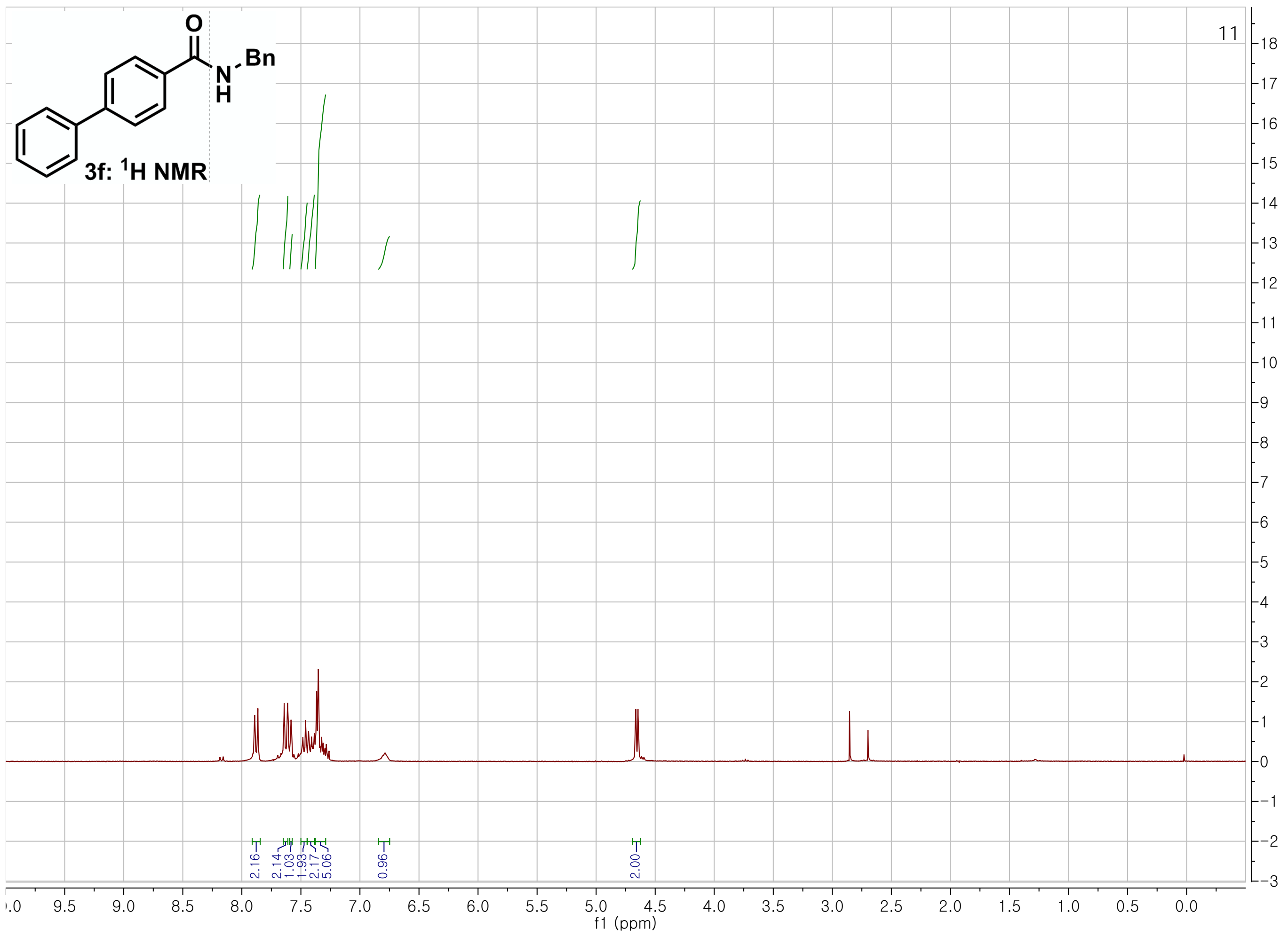




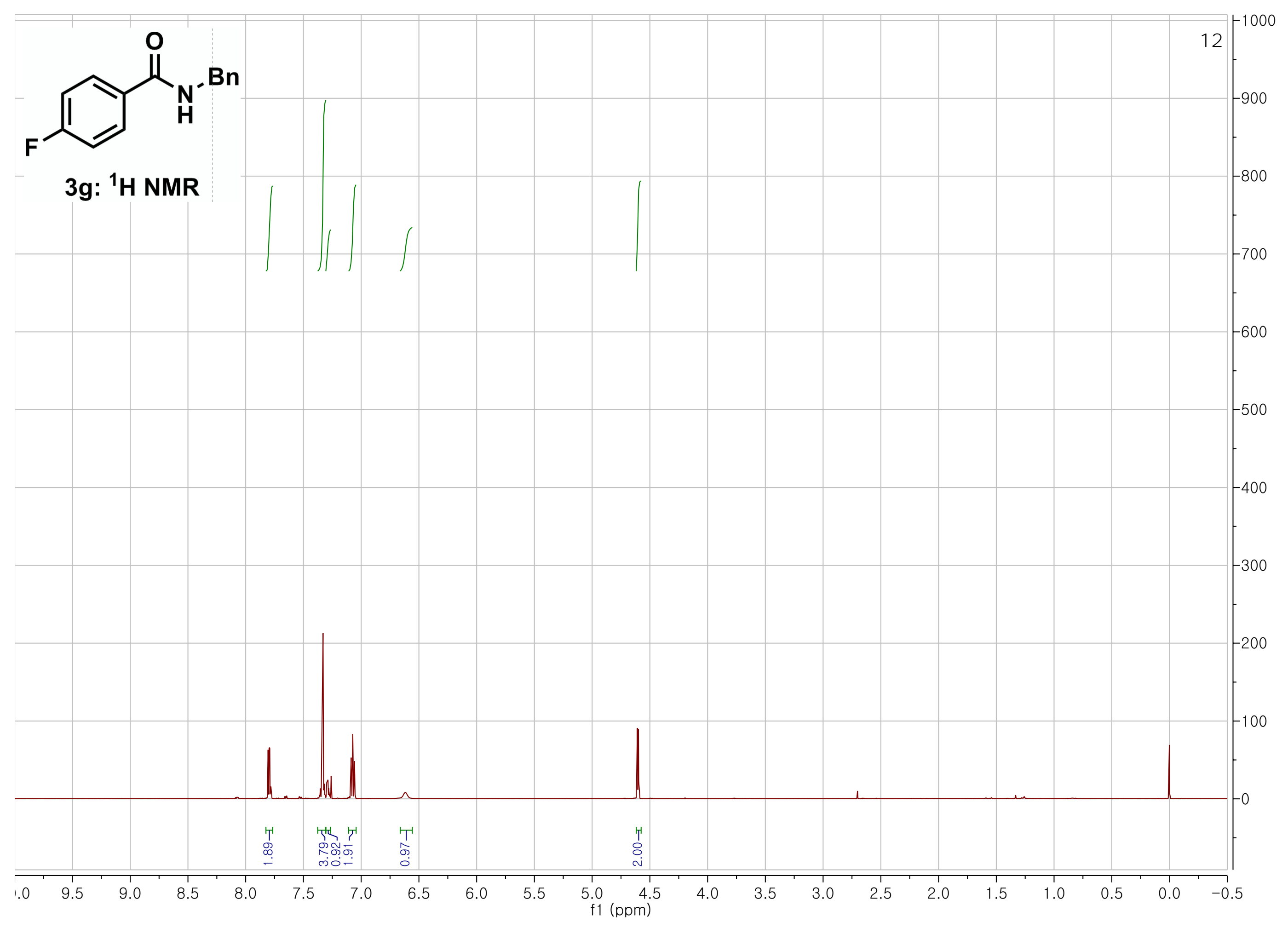




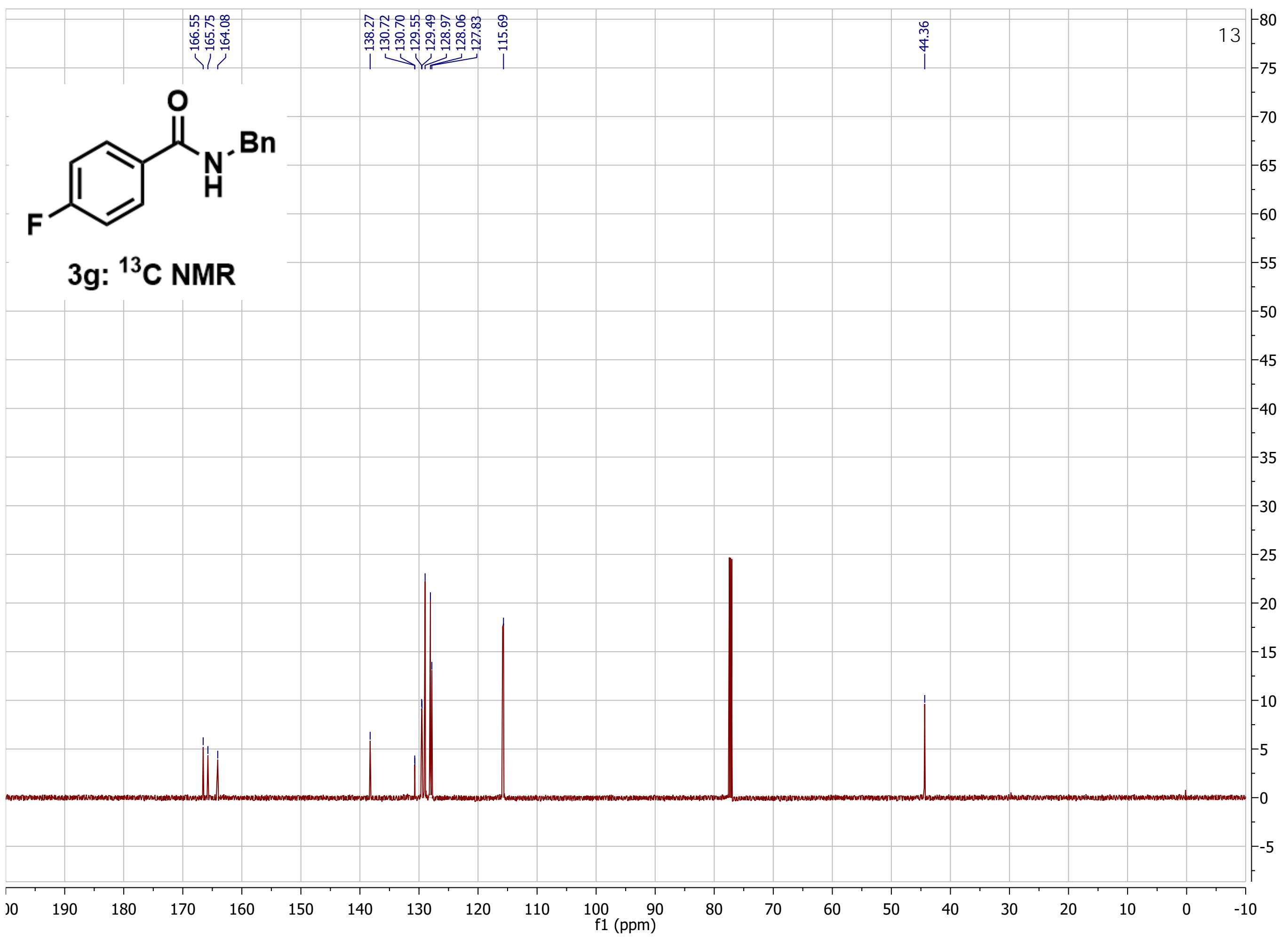




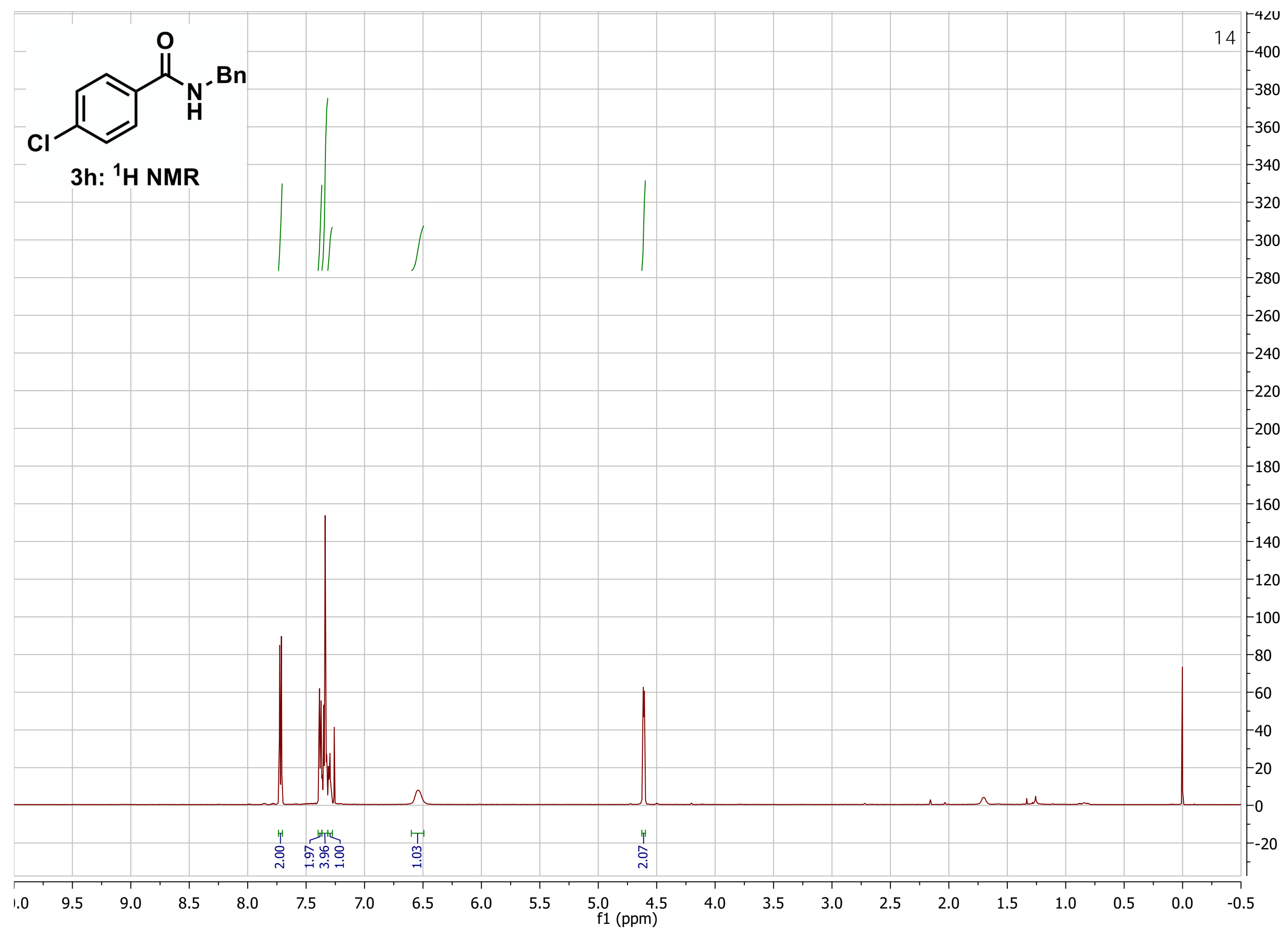




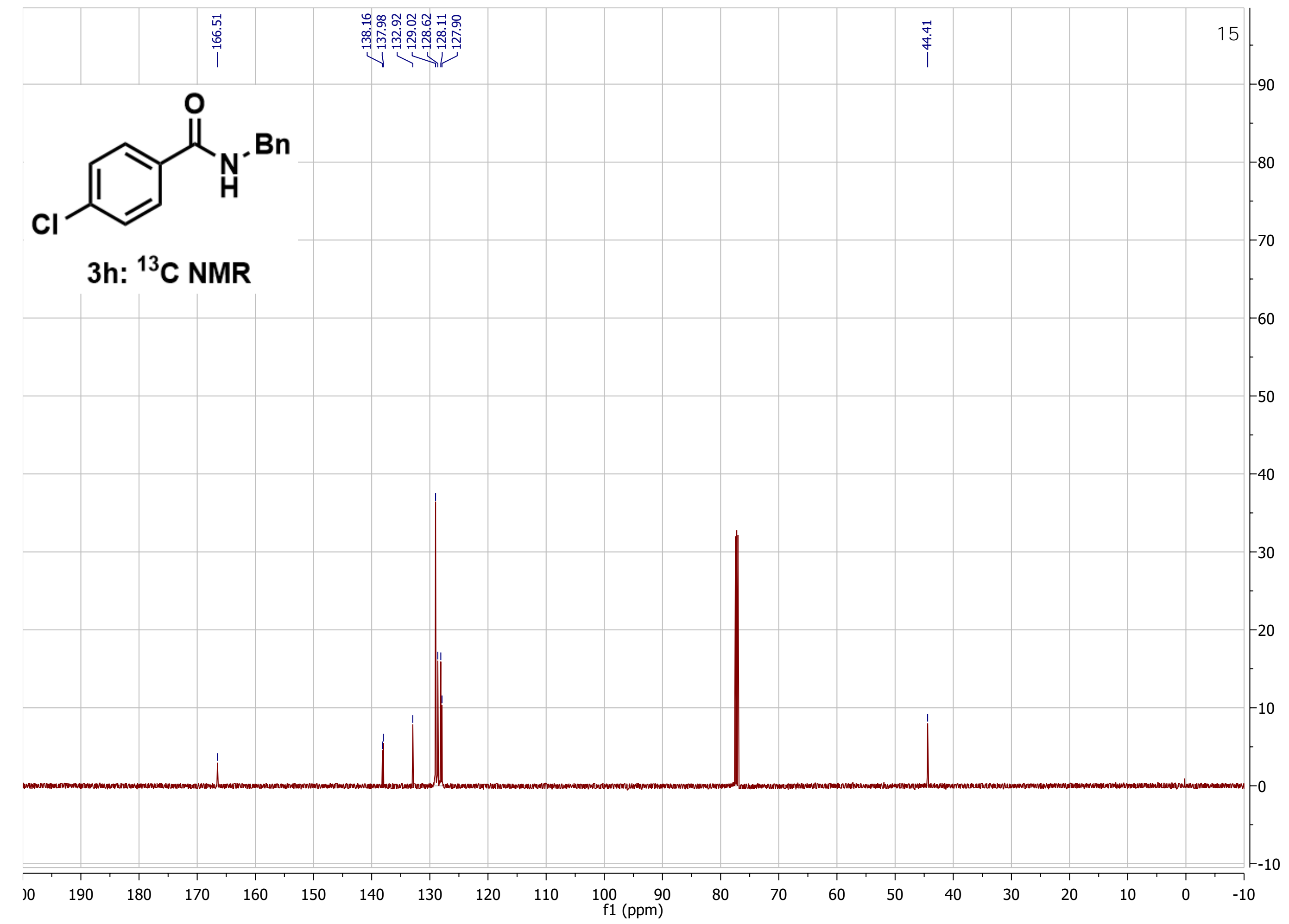




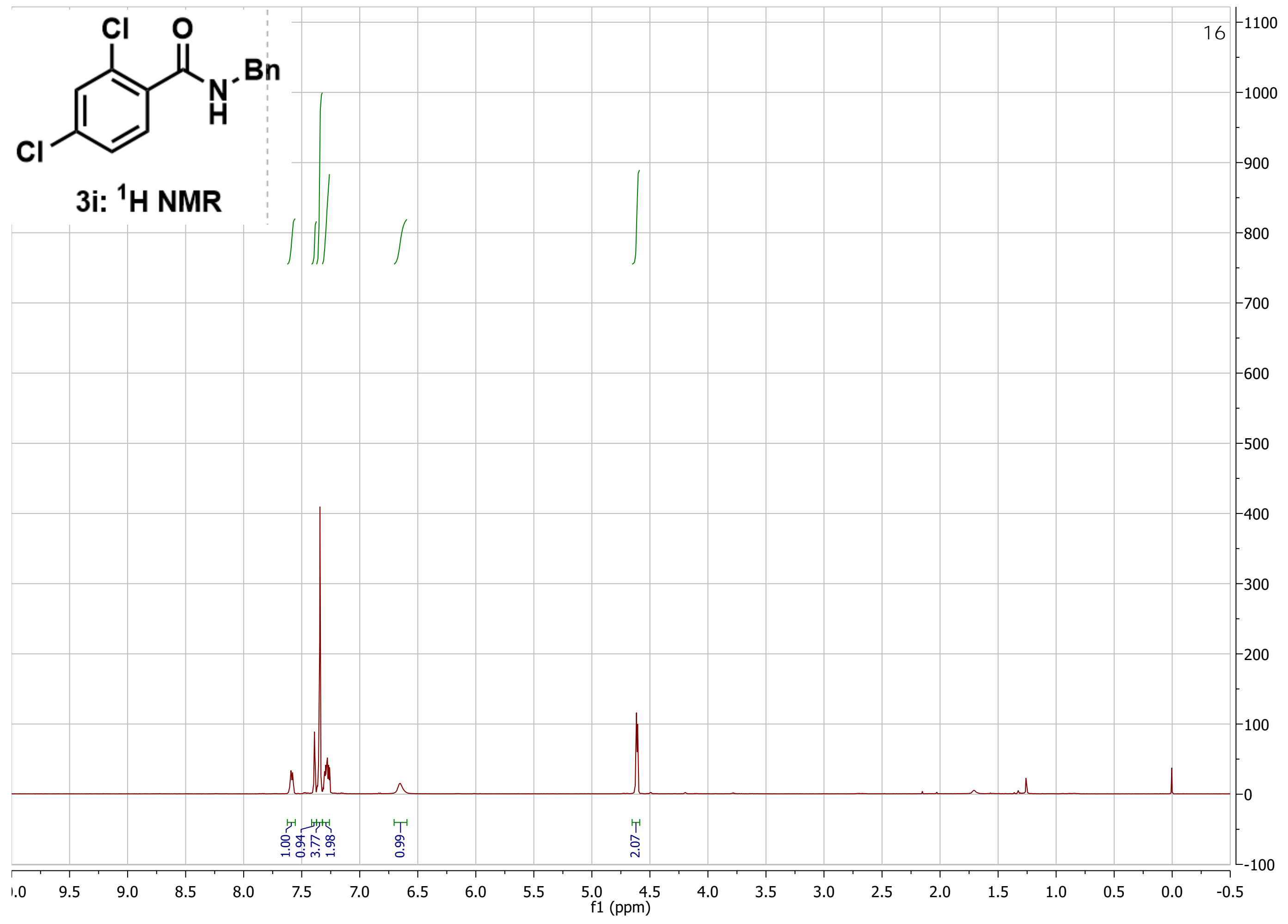




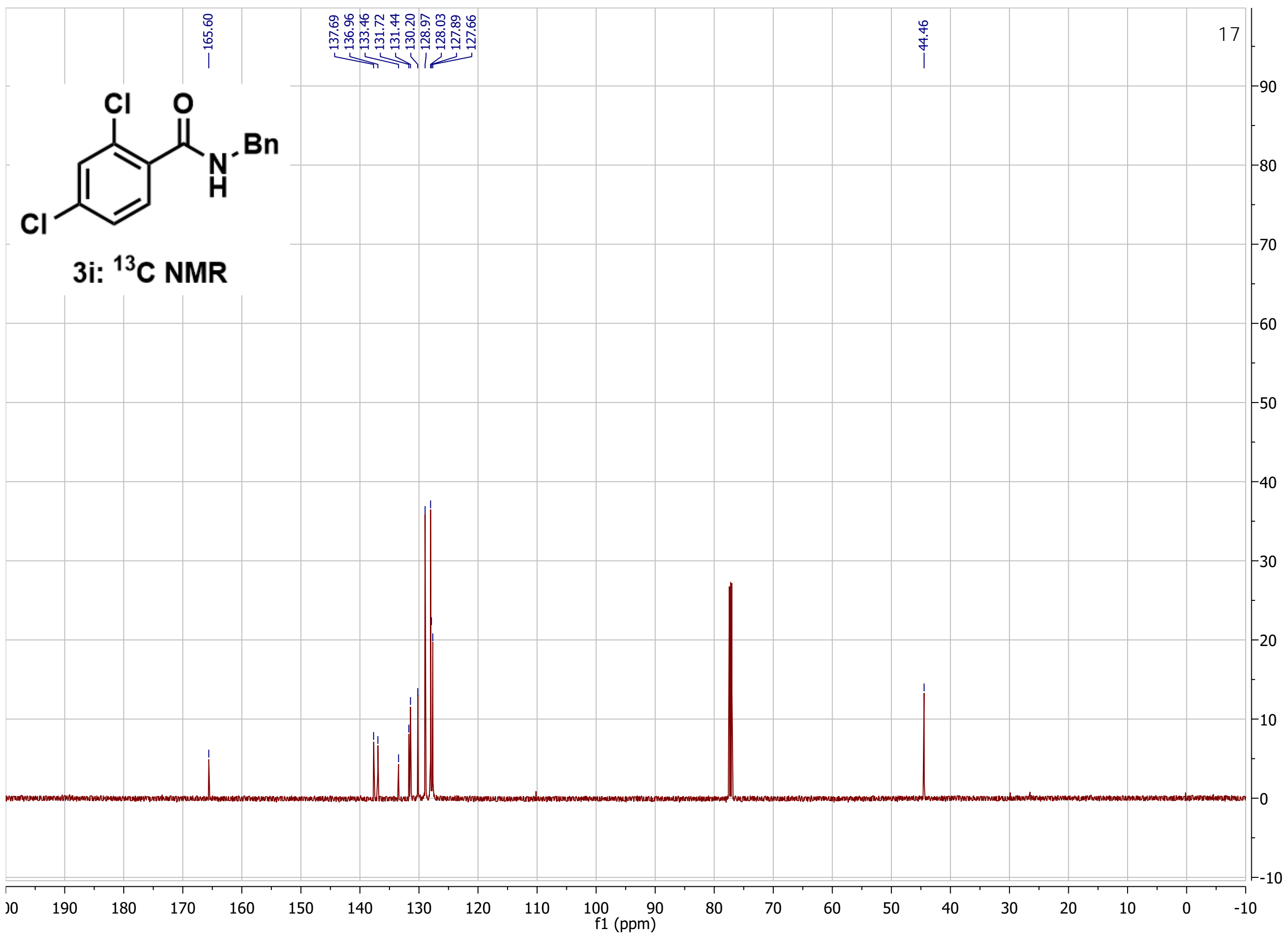




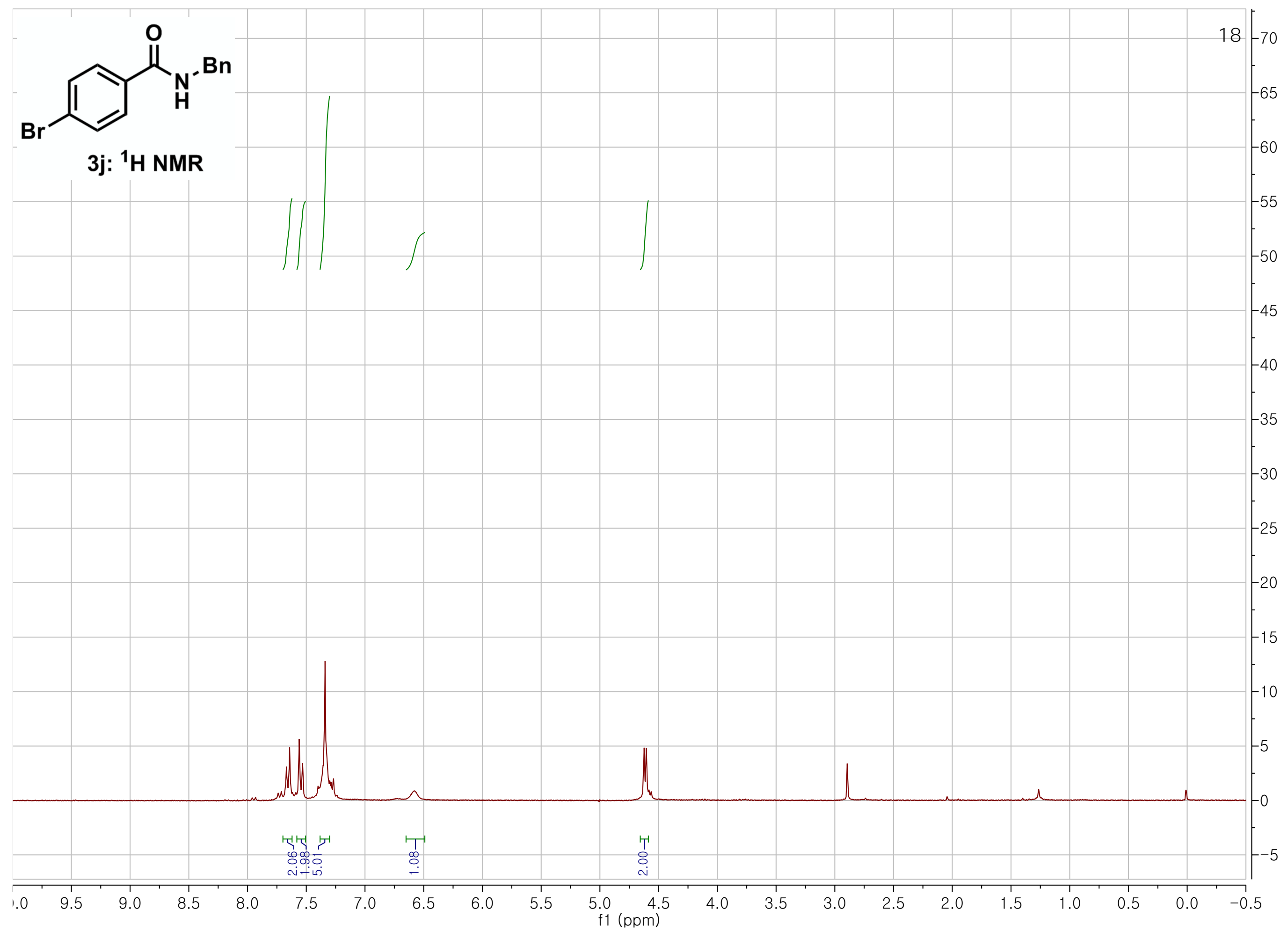



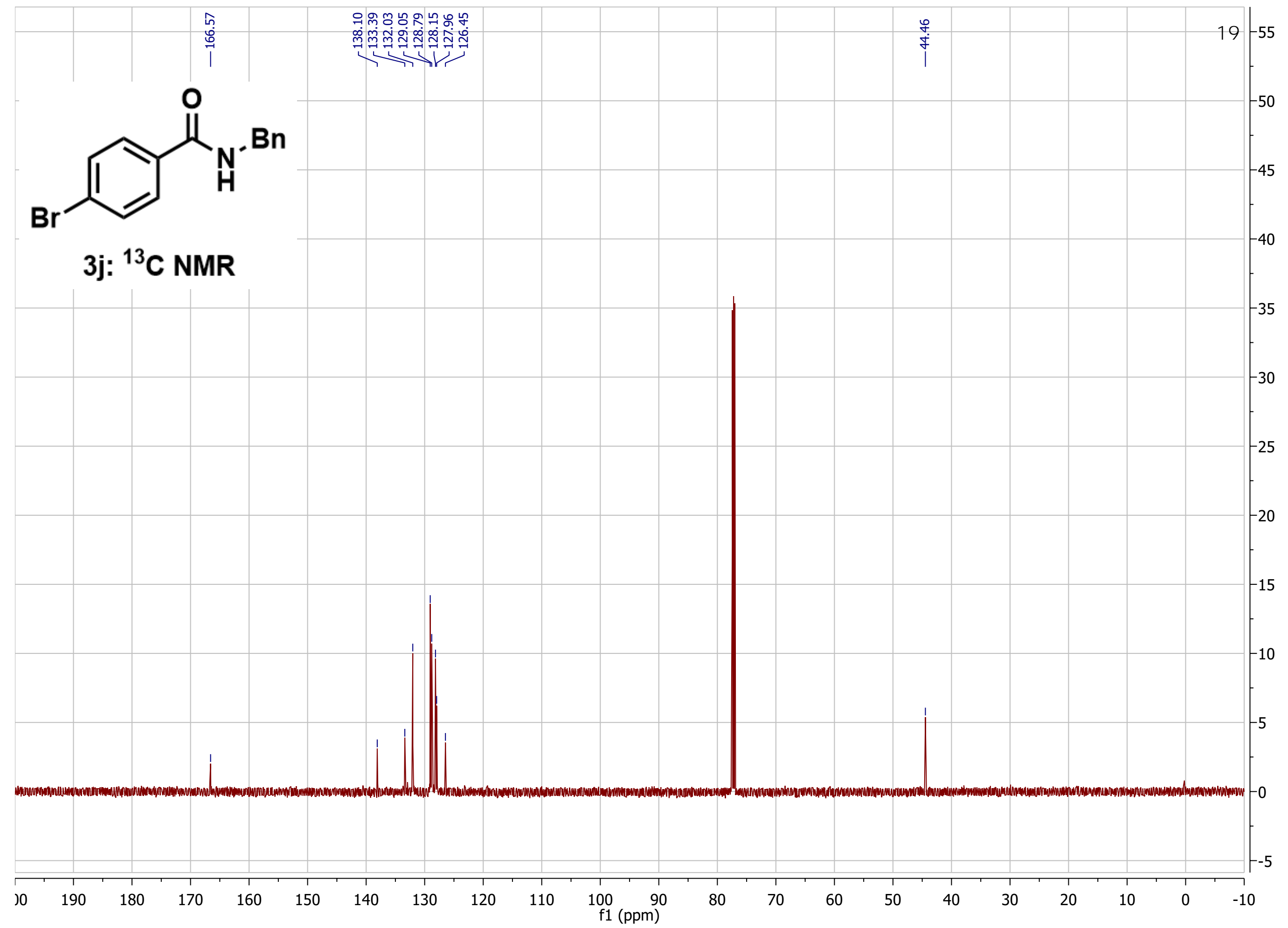


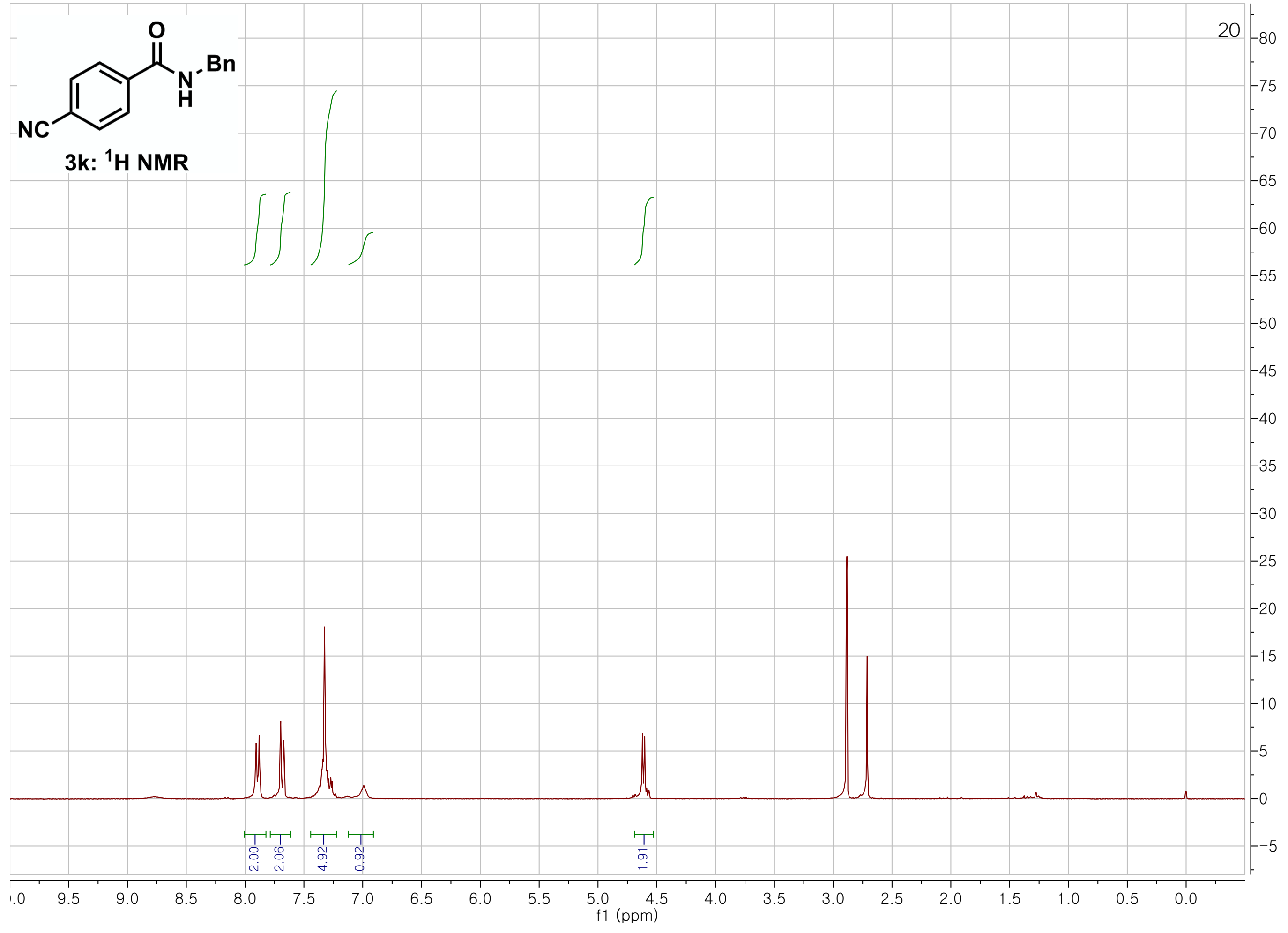




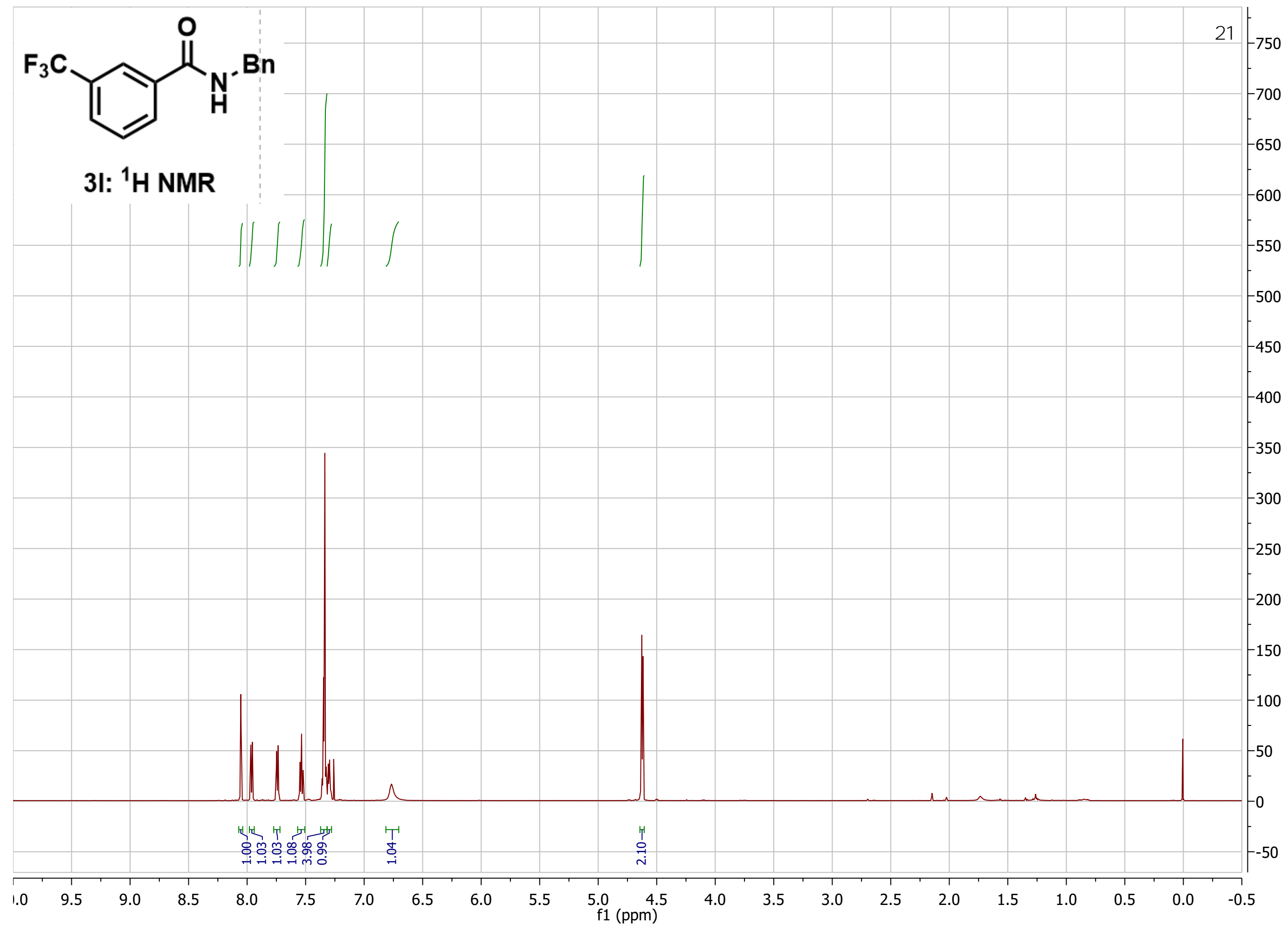




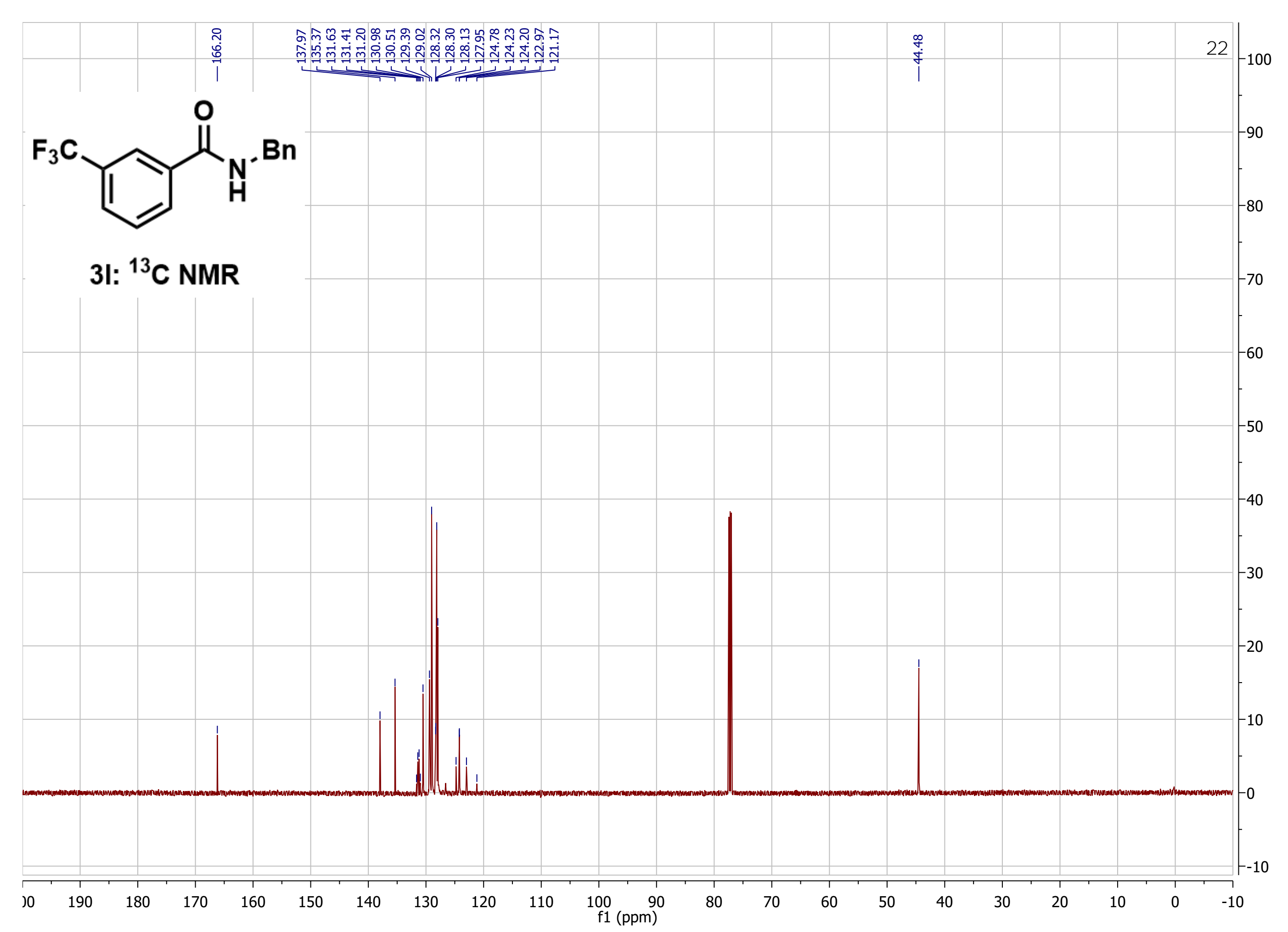




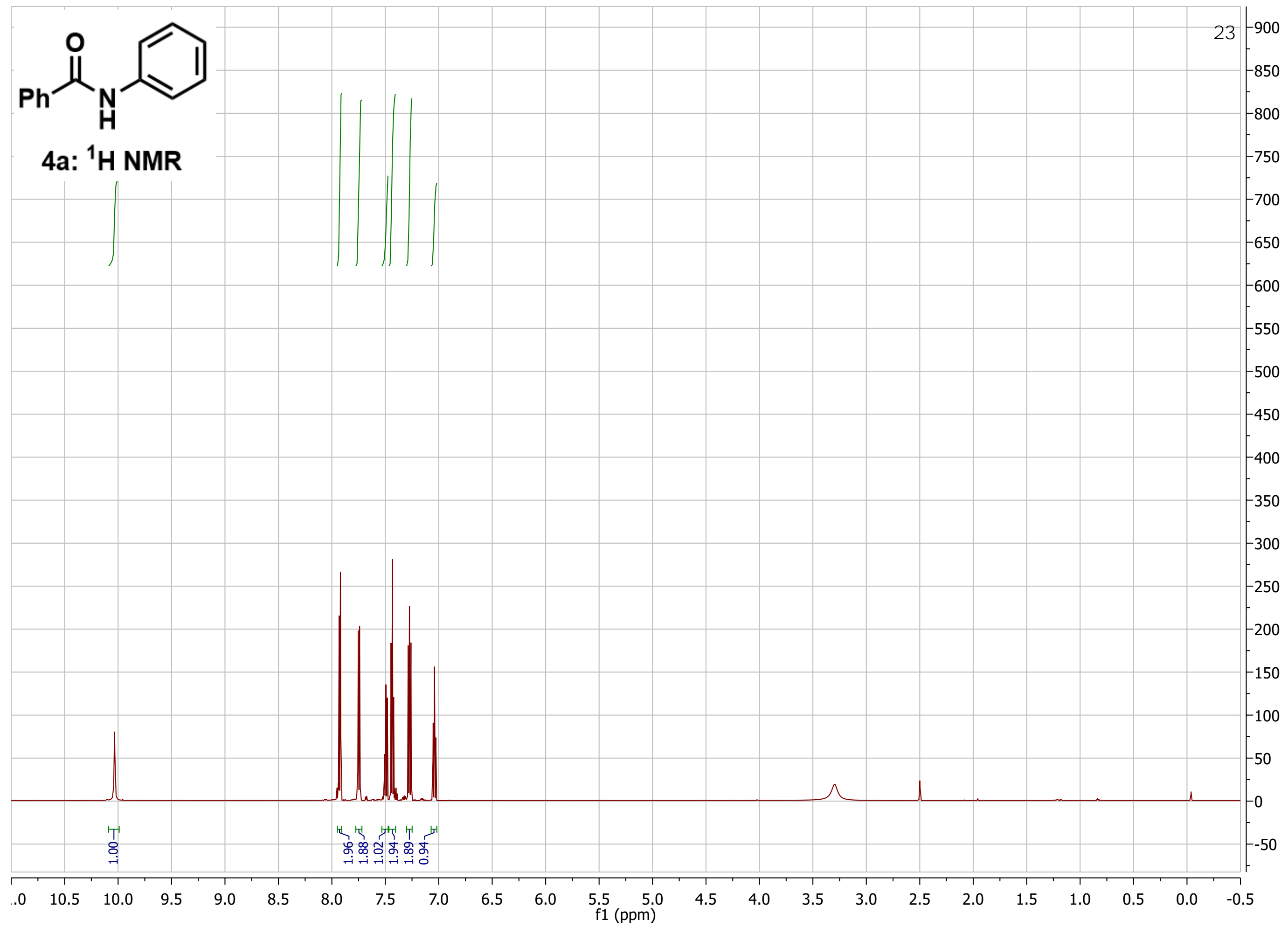




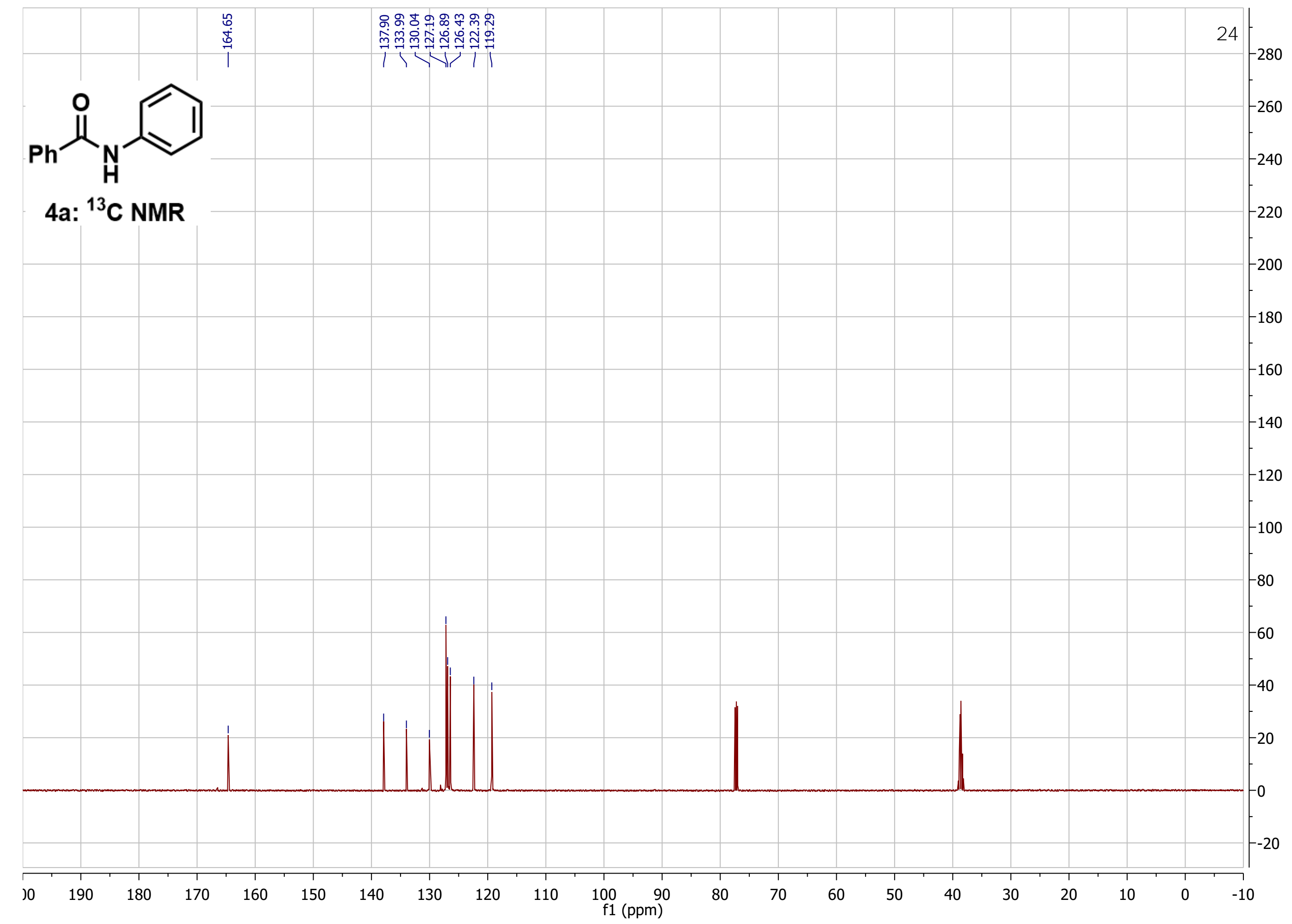




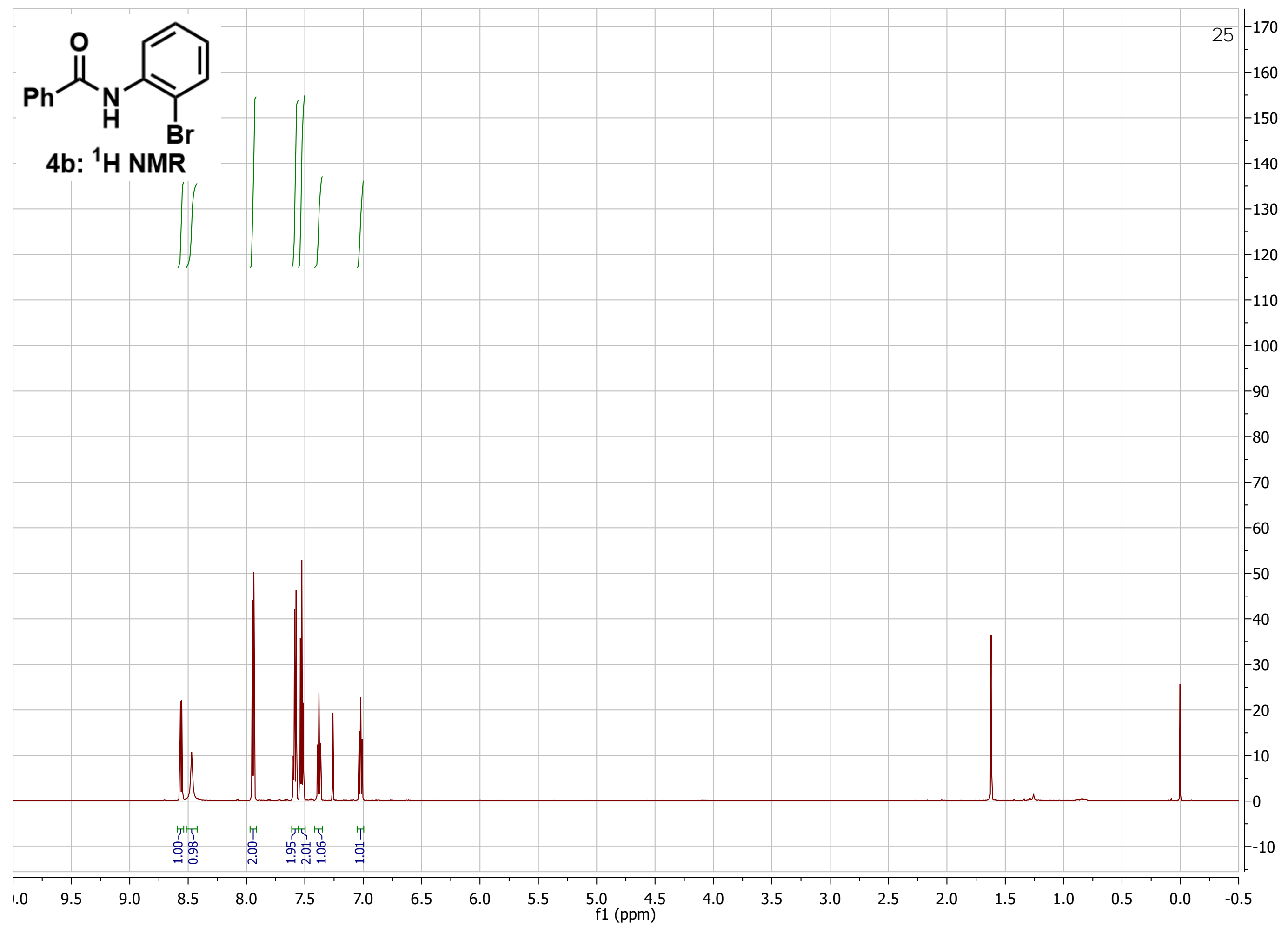




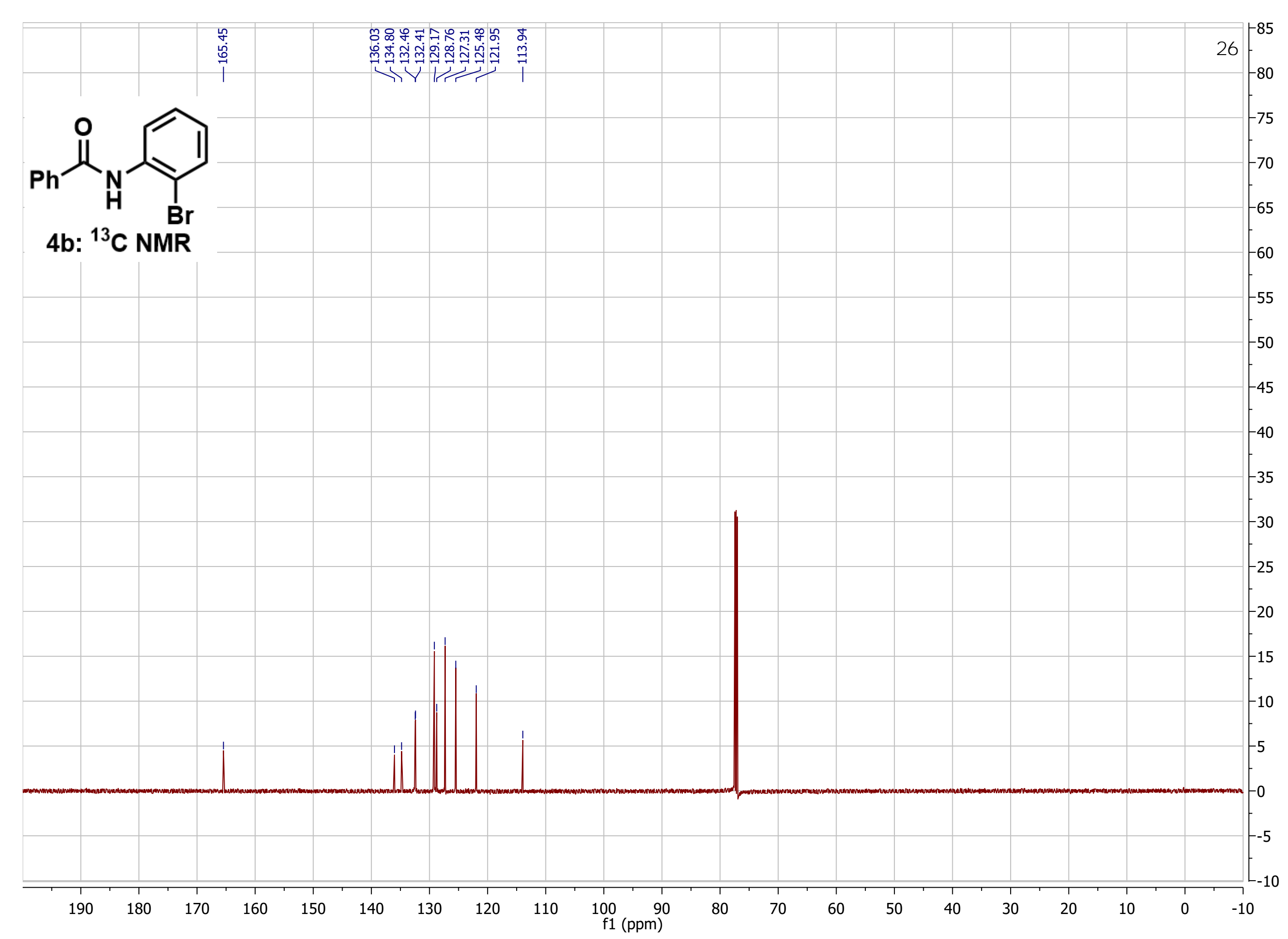




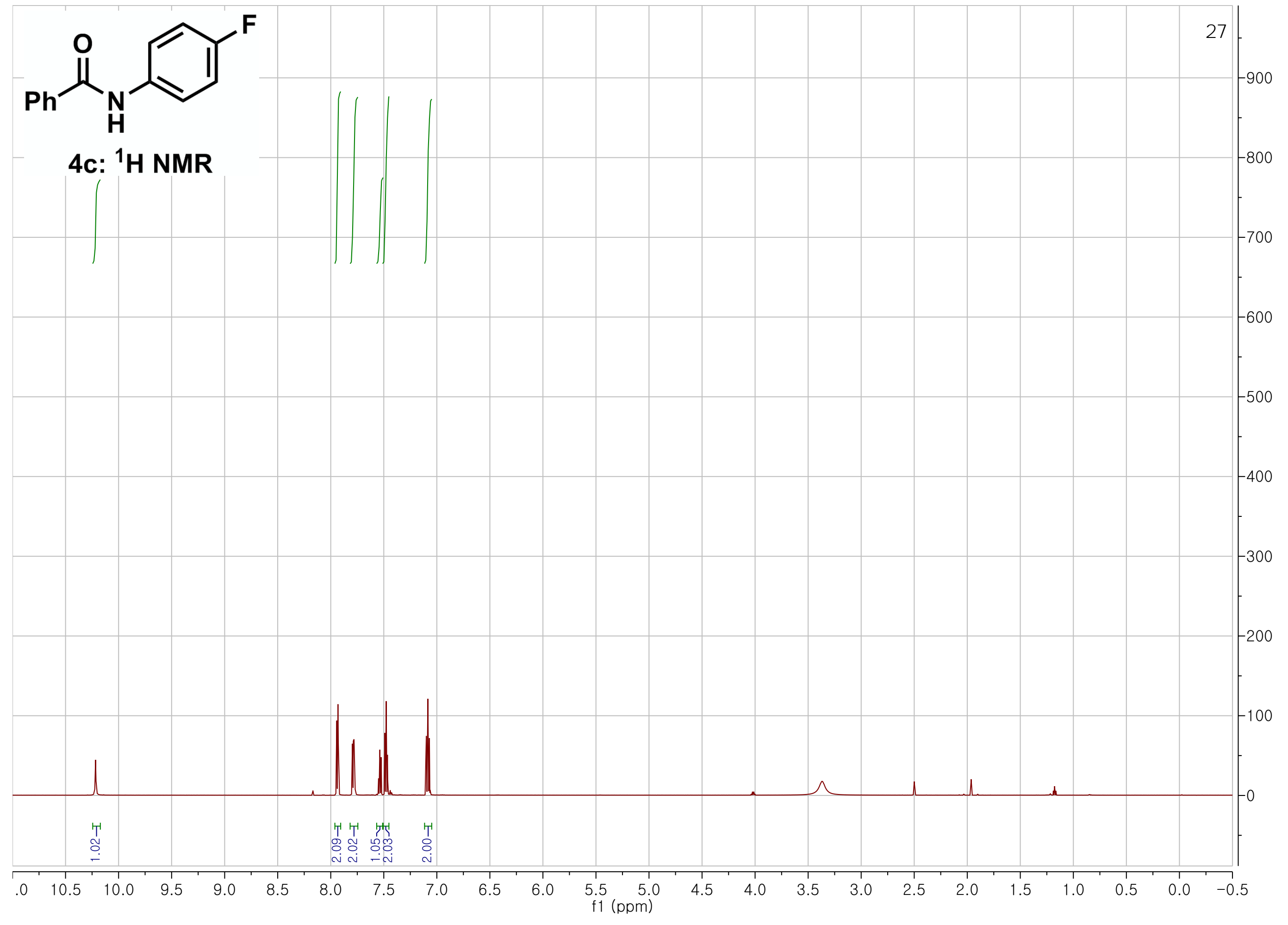




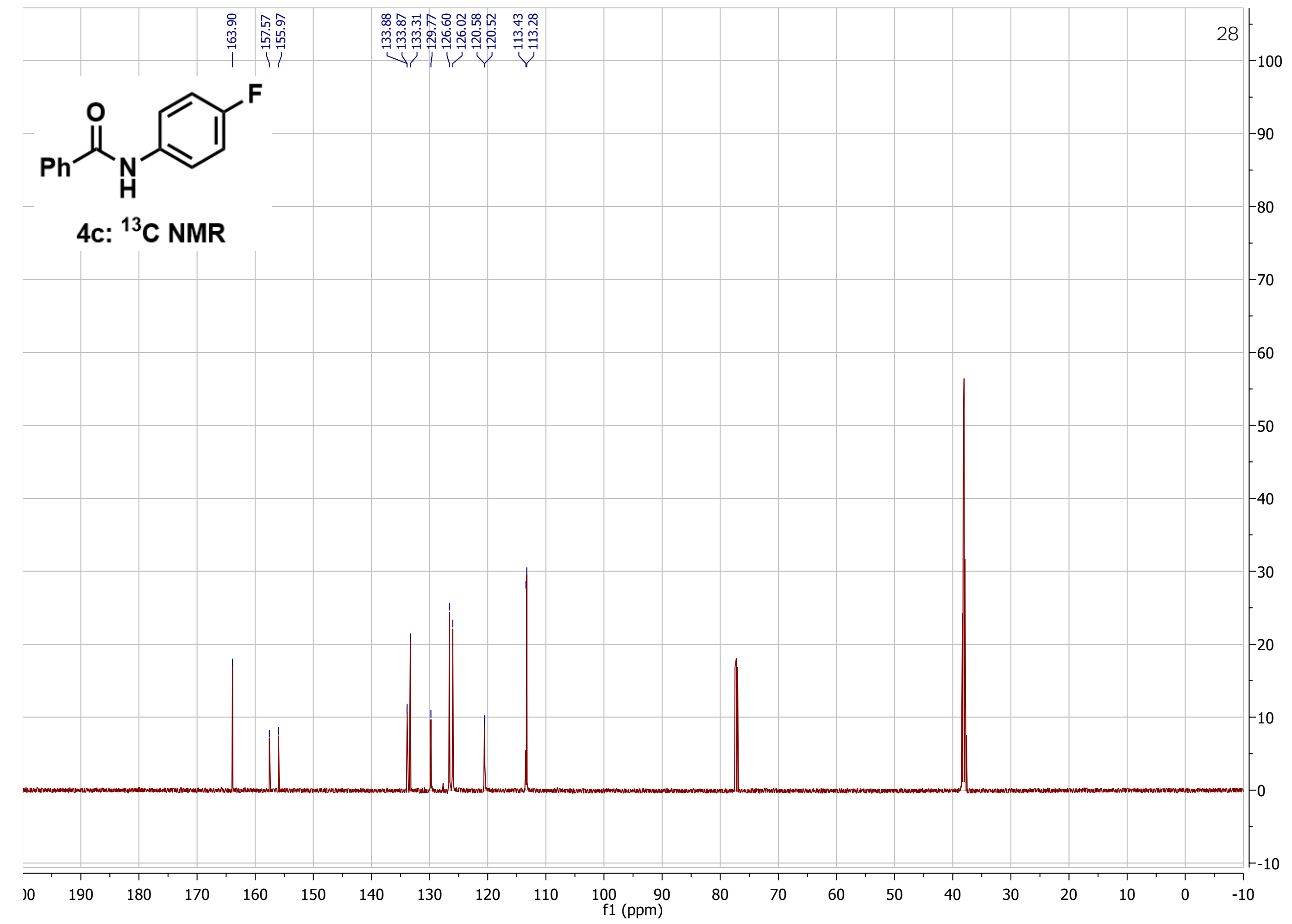




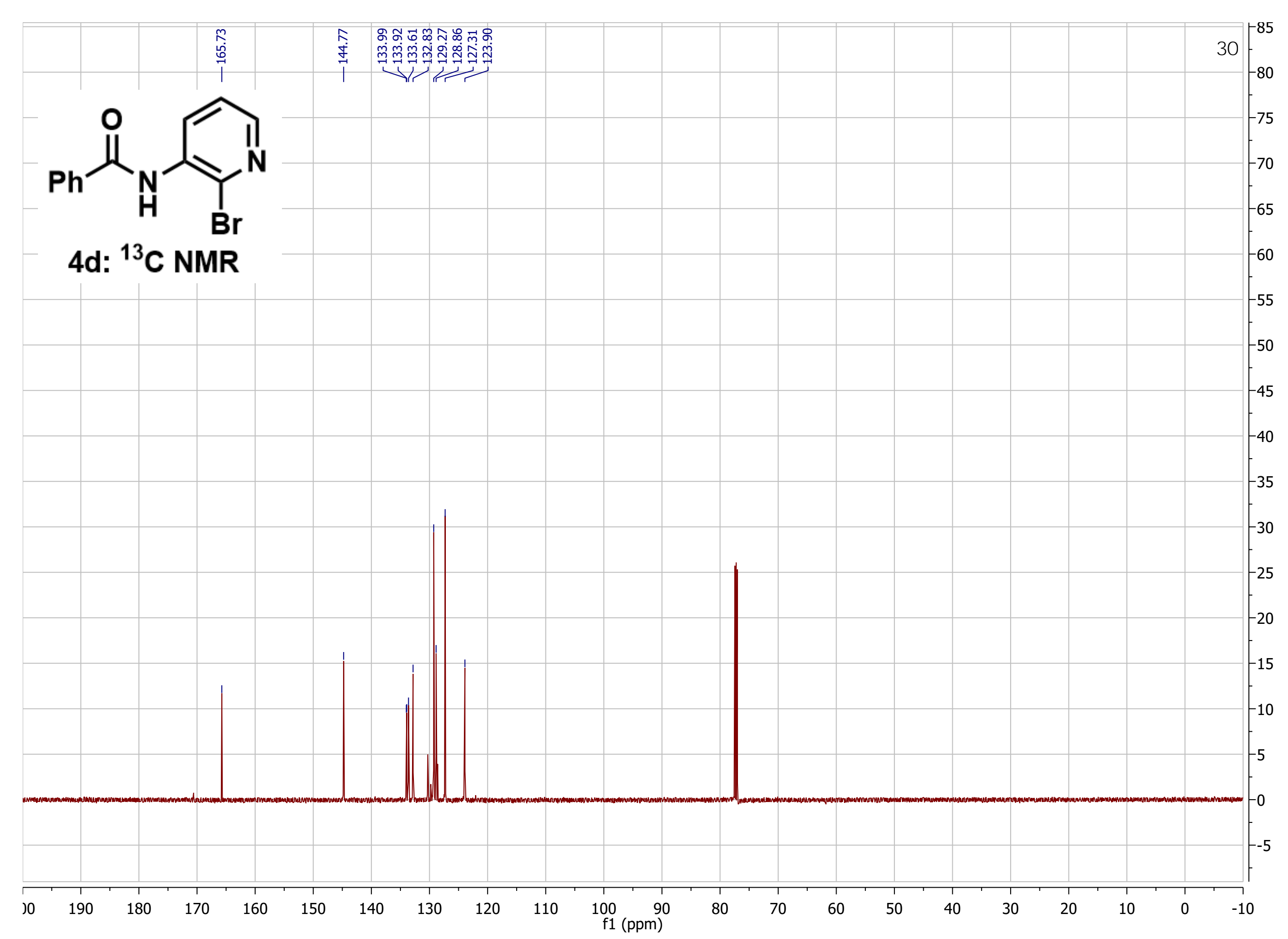




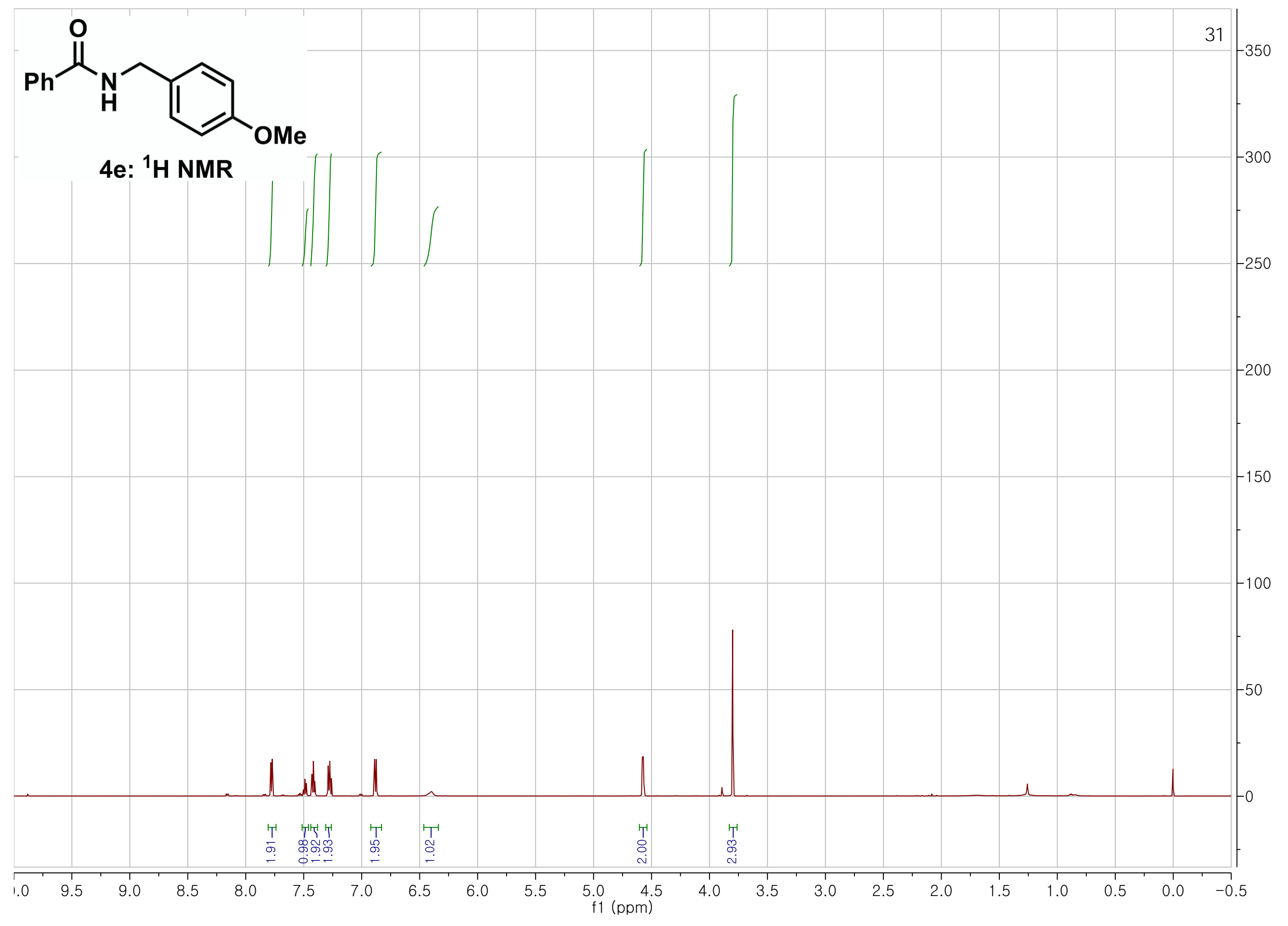




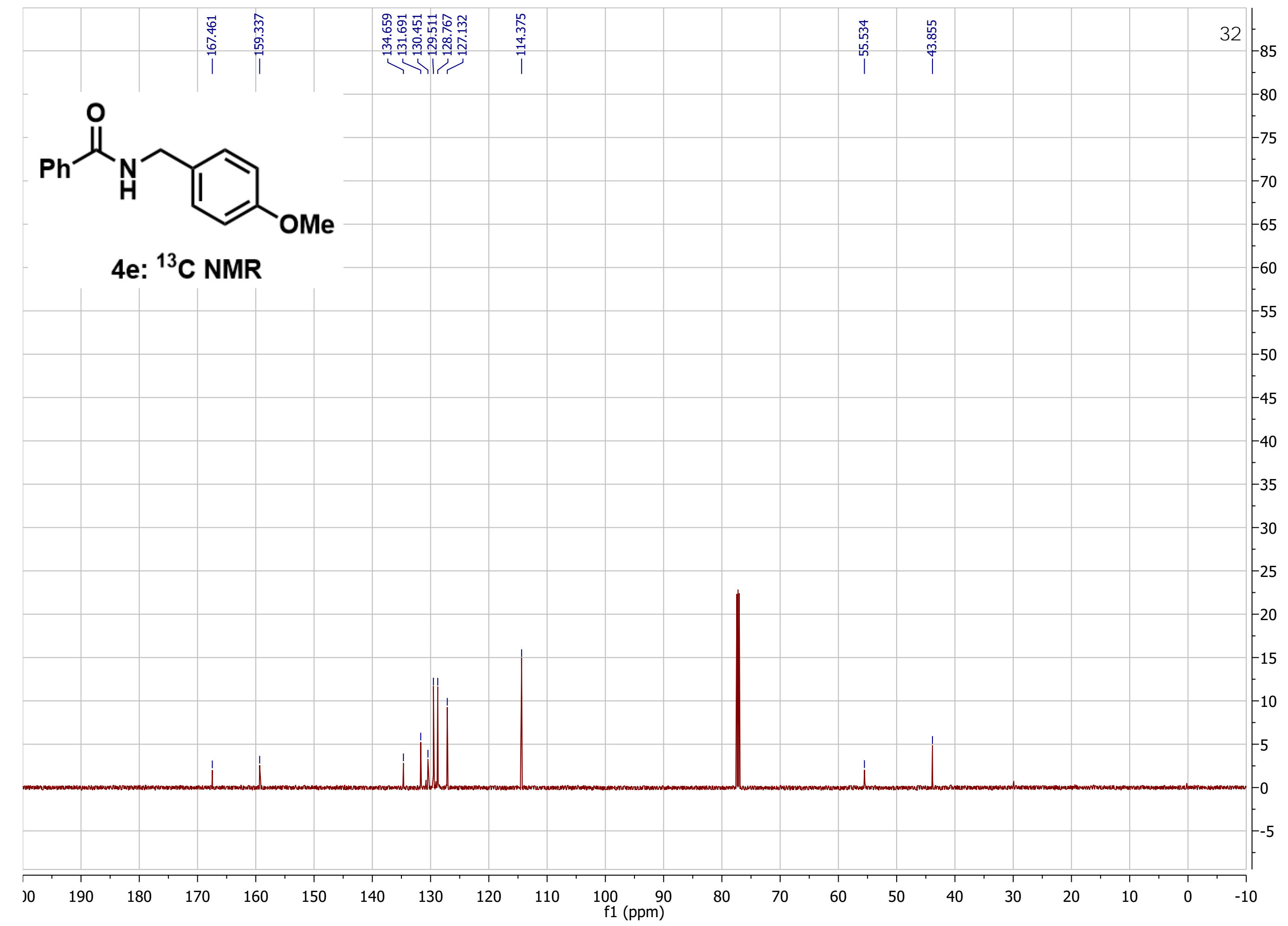




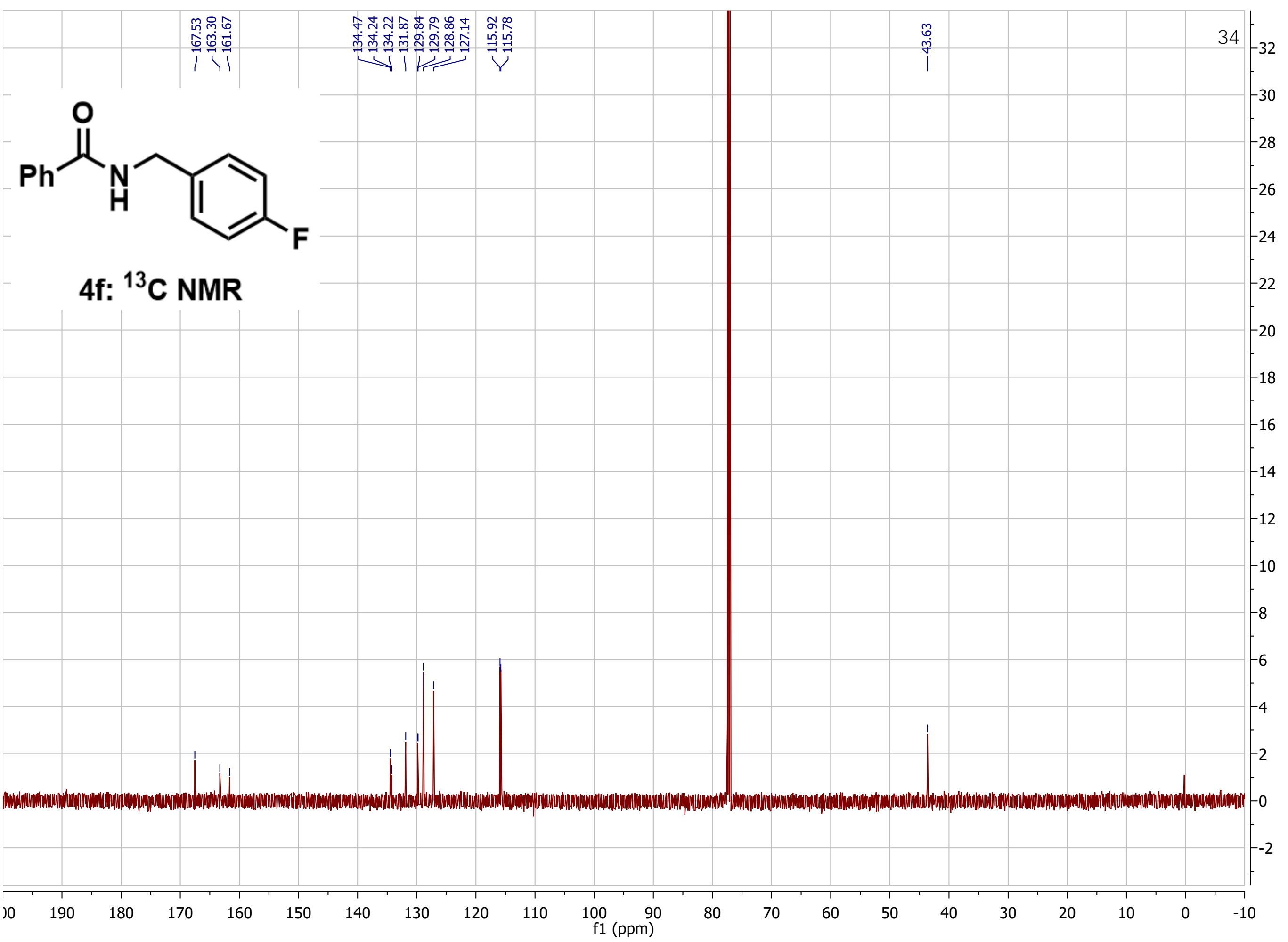




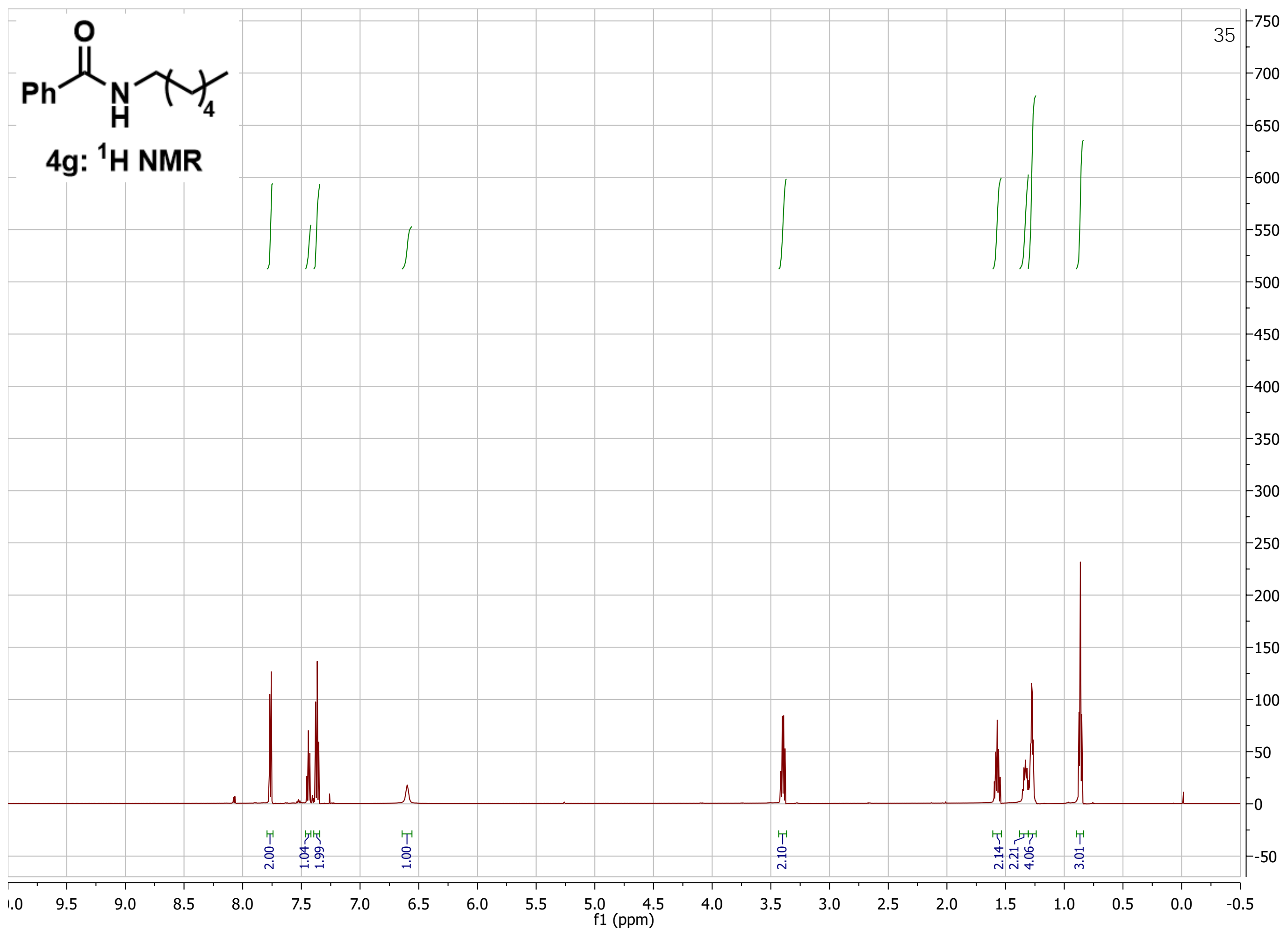




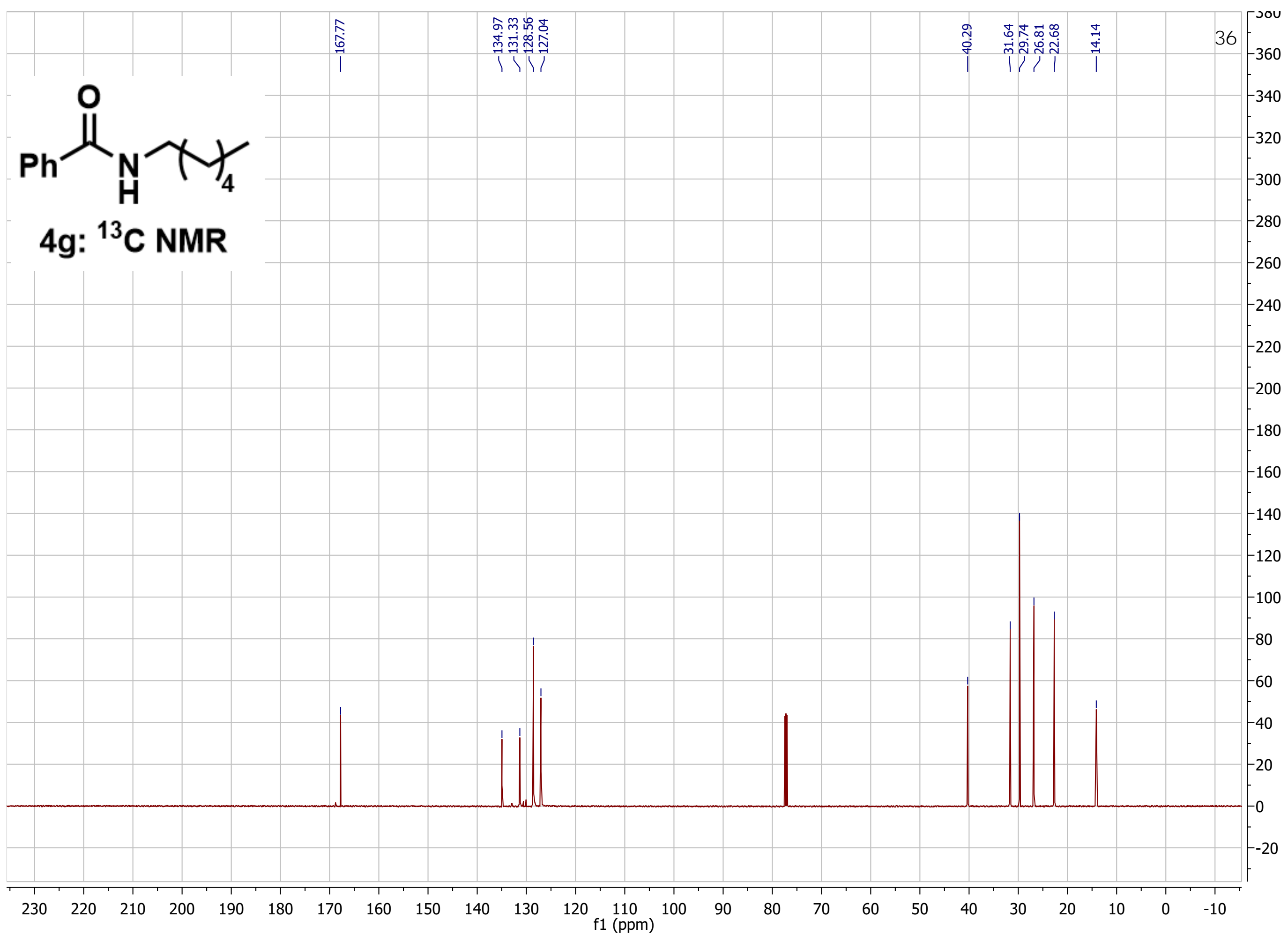




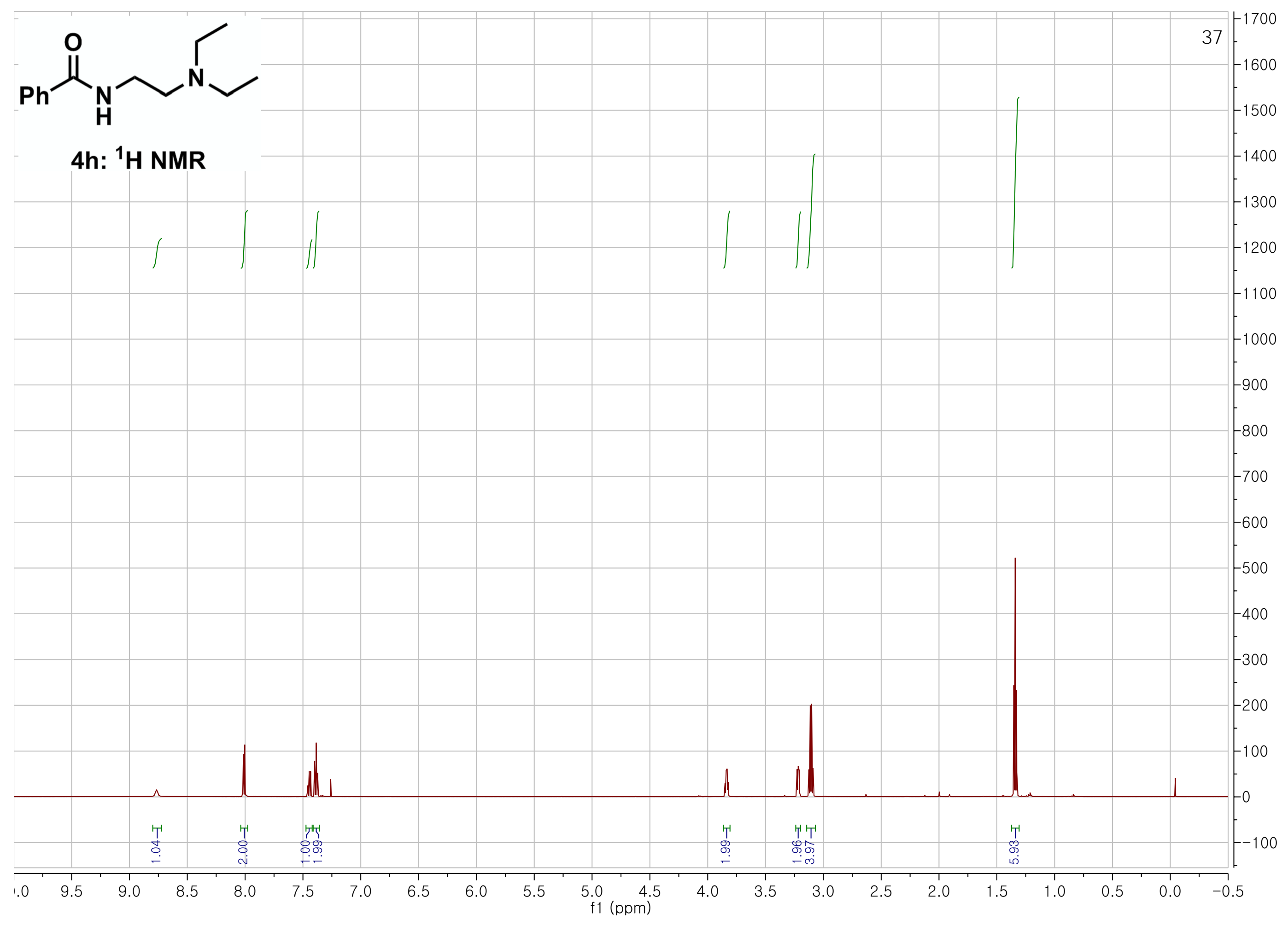




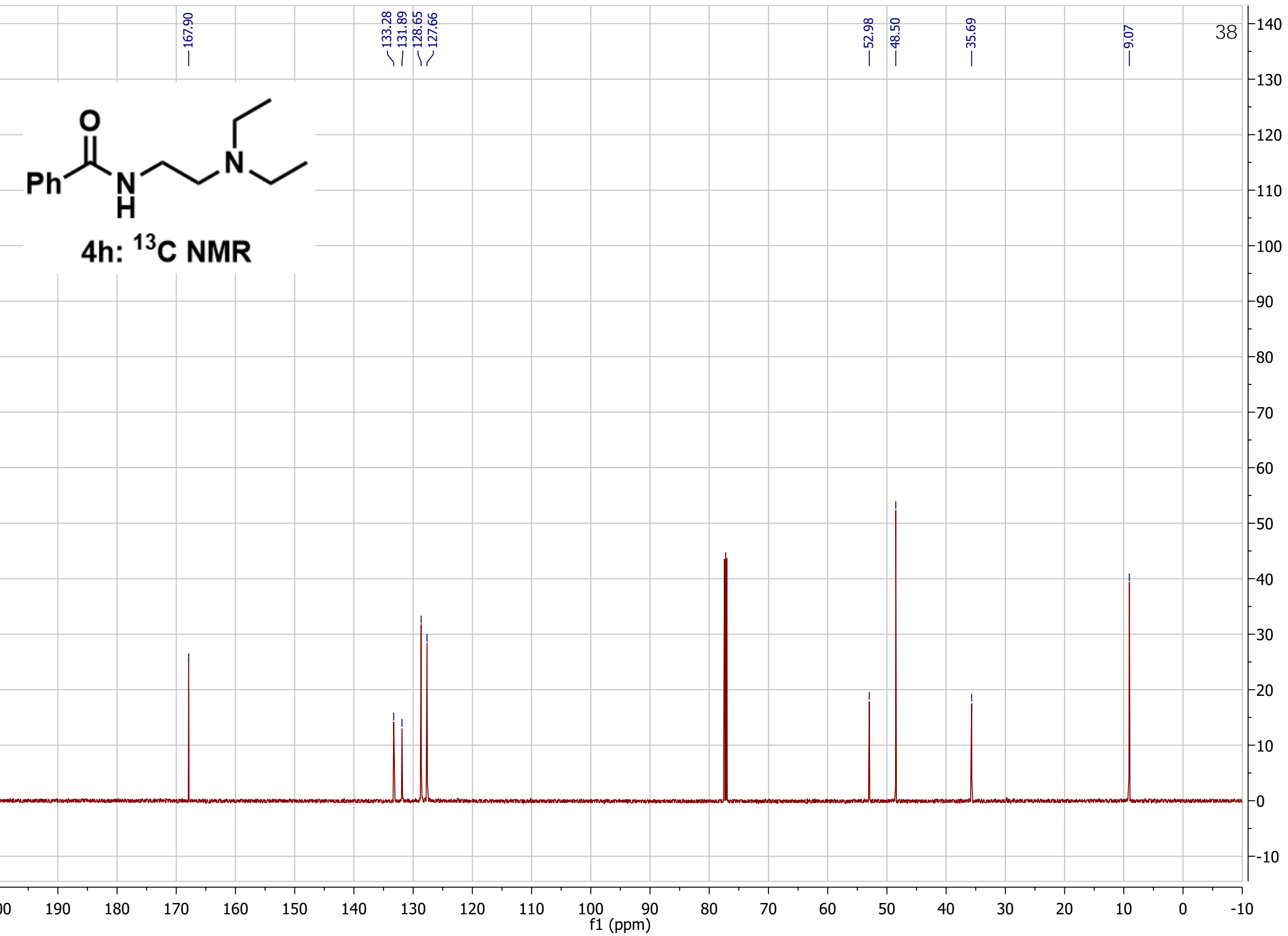




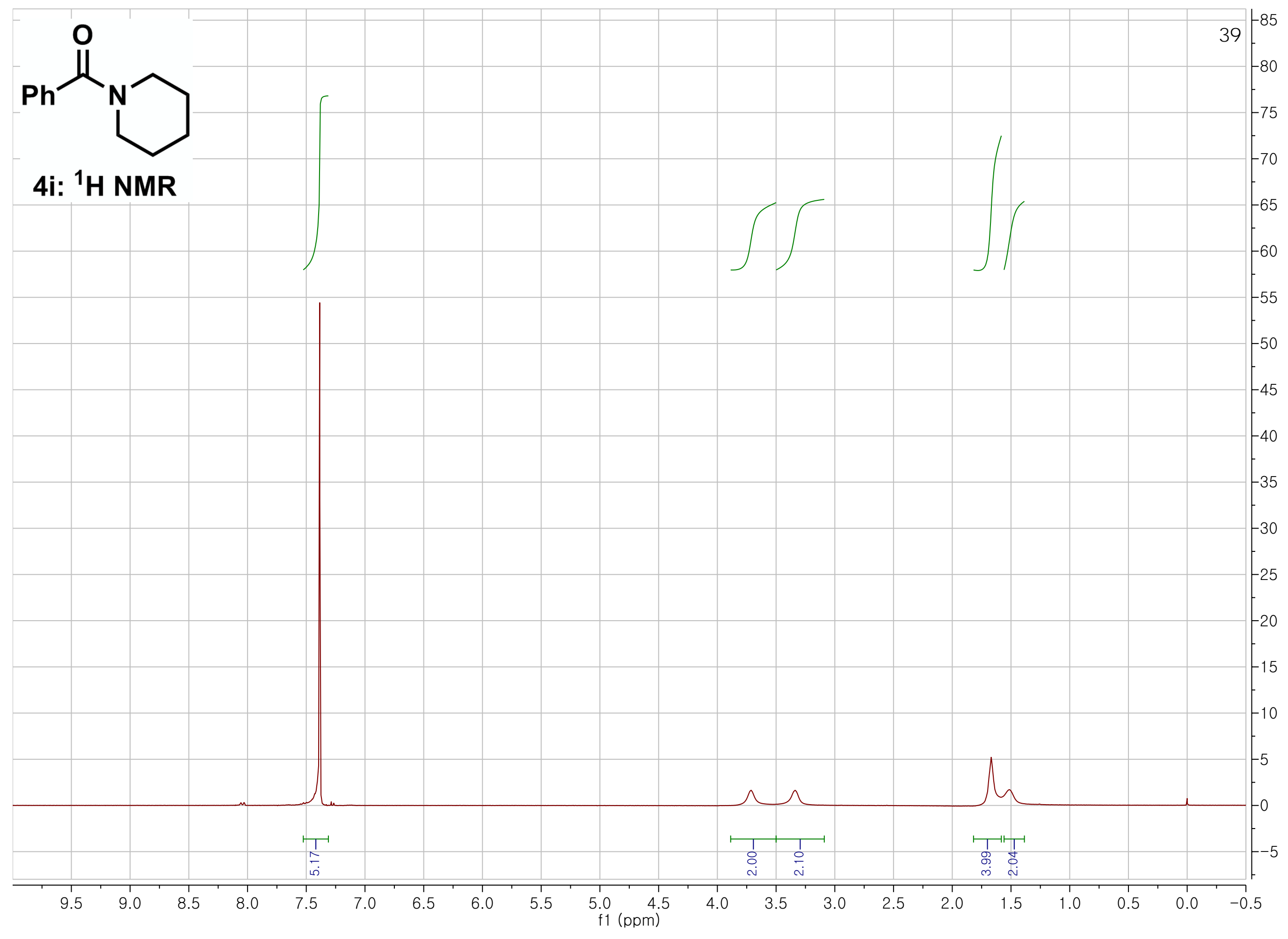




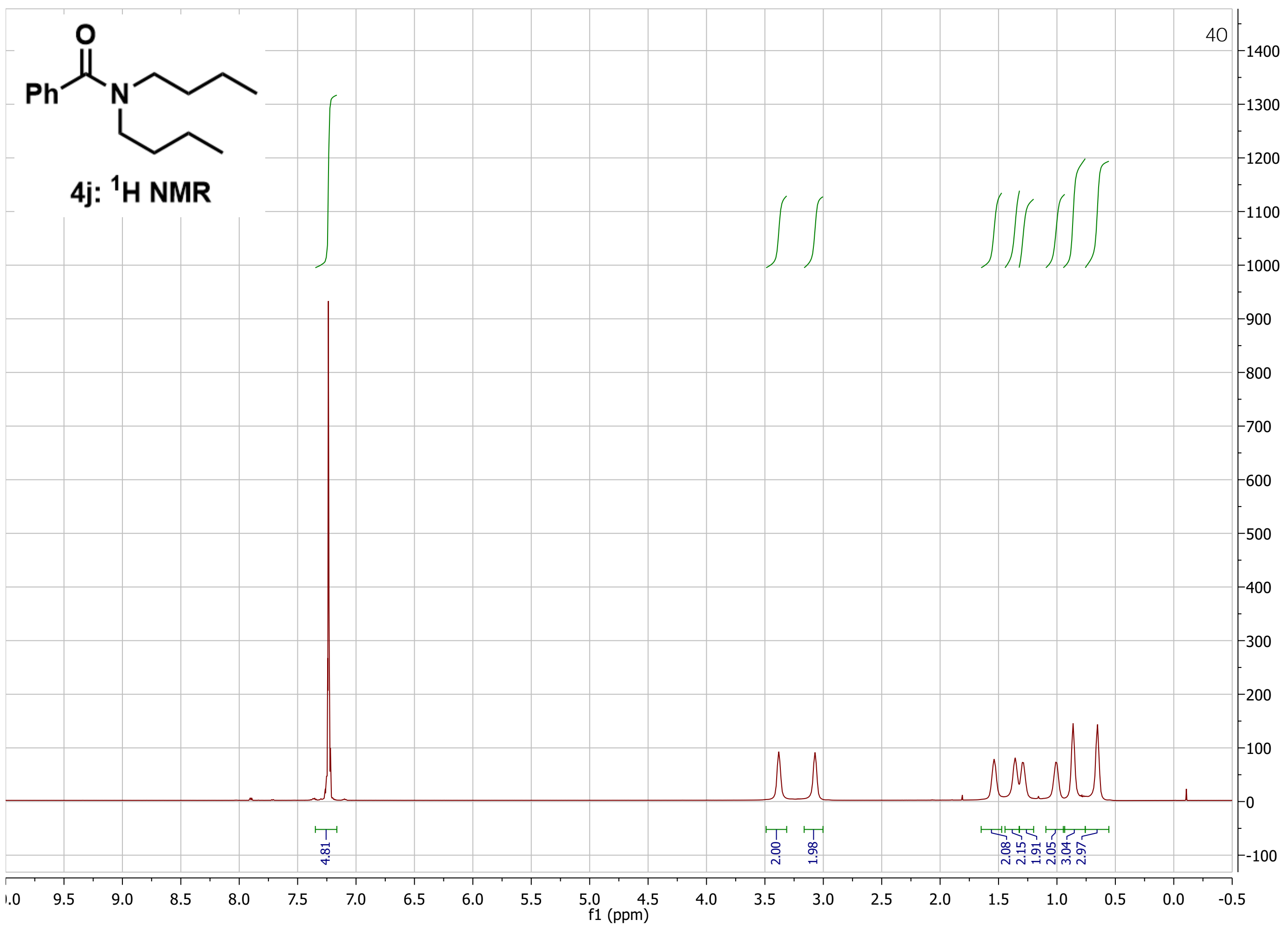




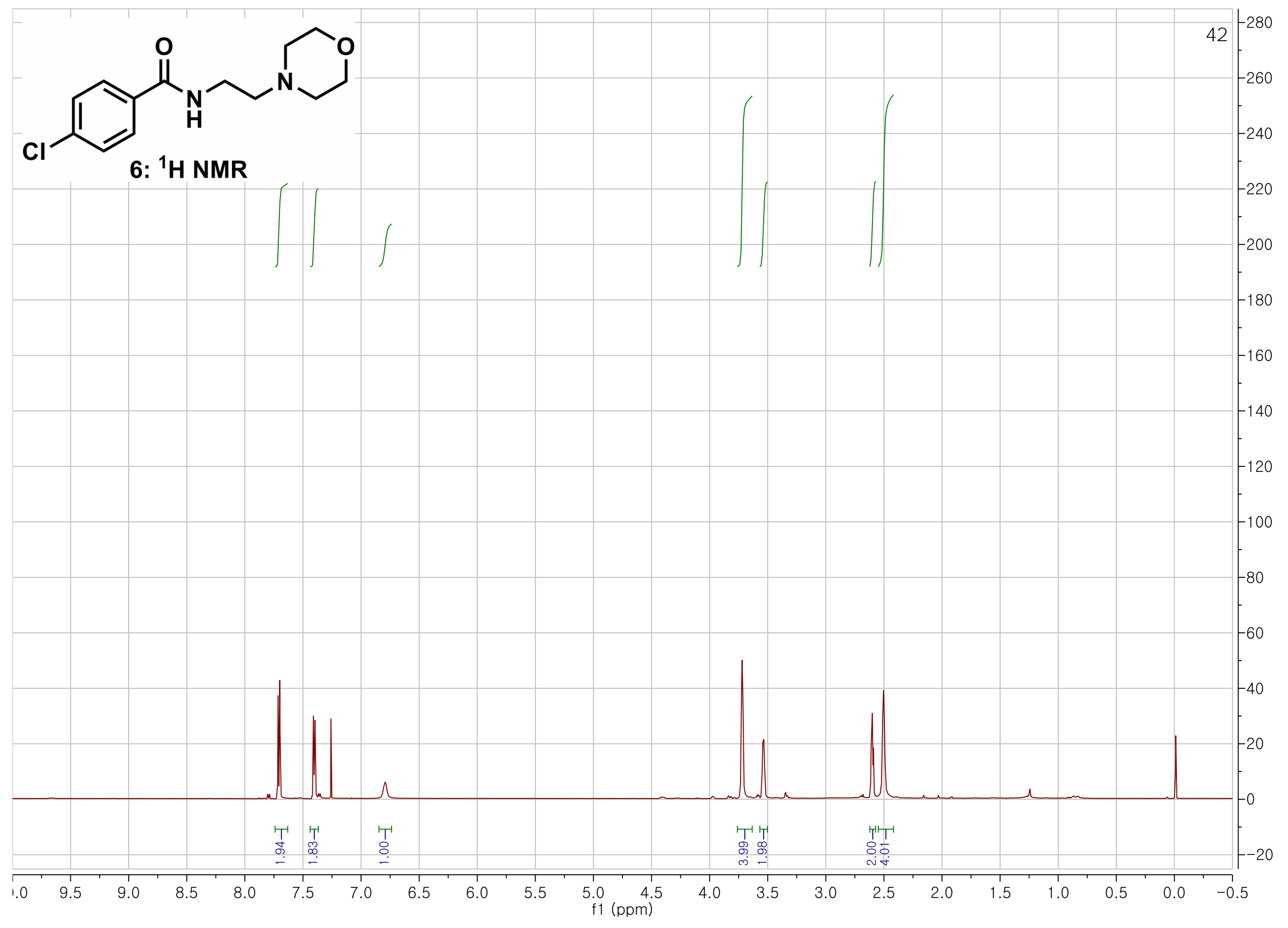




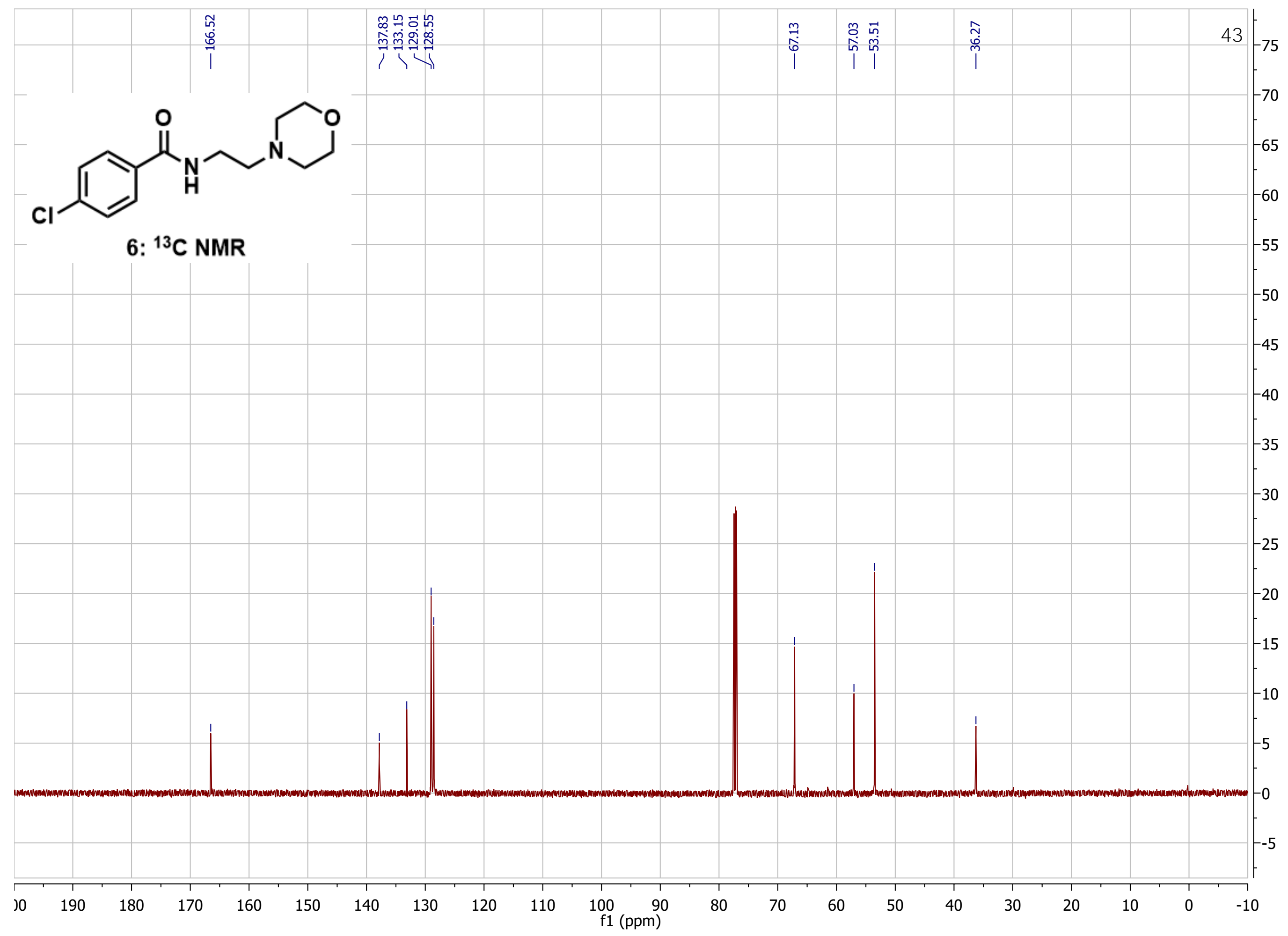




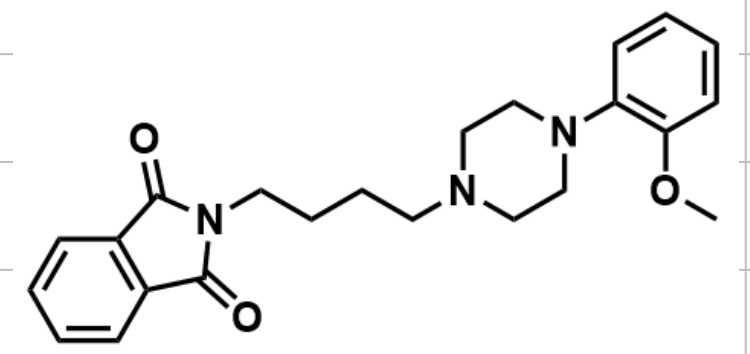

9: ${ }^{1} \mathrm{H}$ NMR

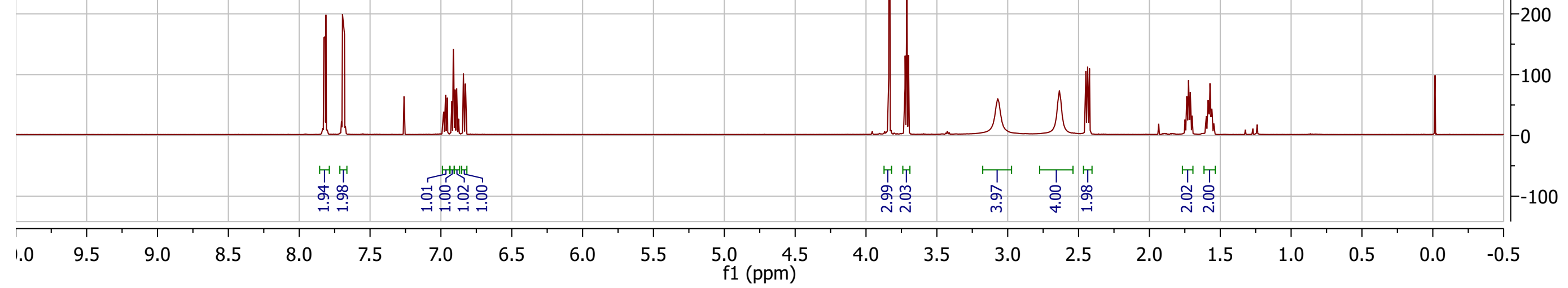




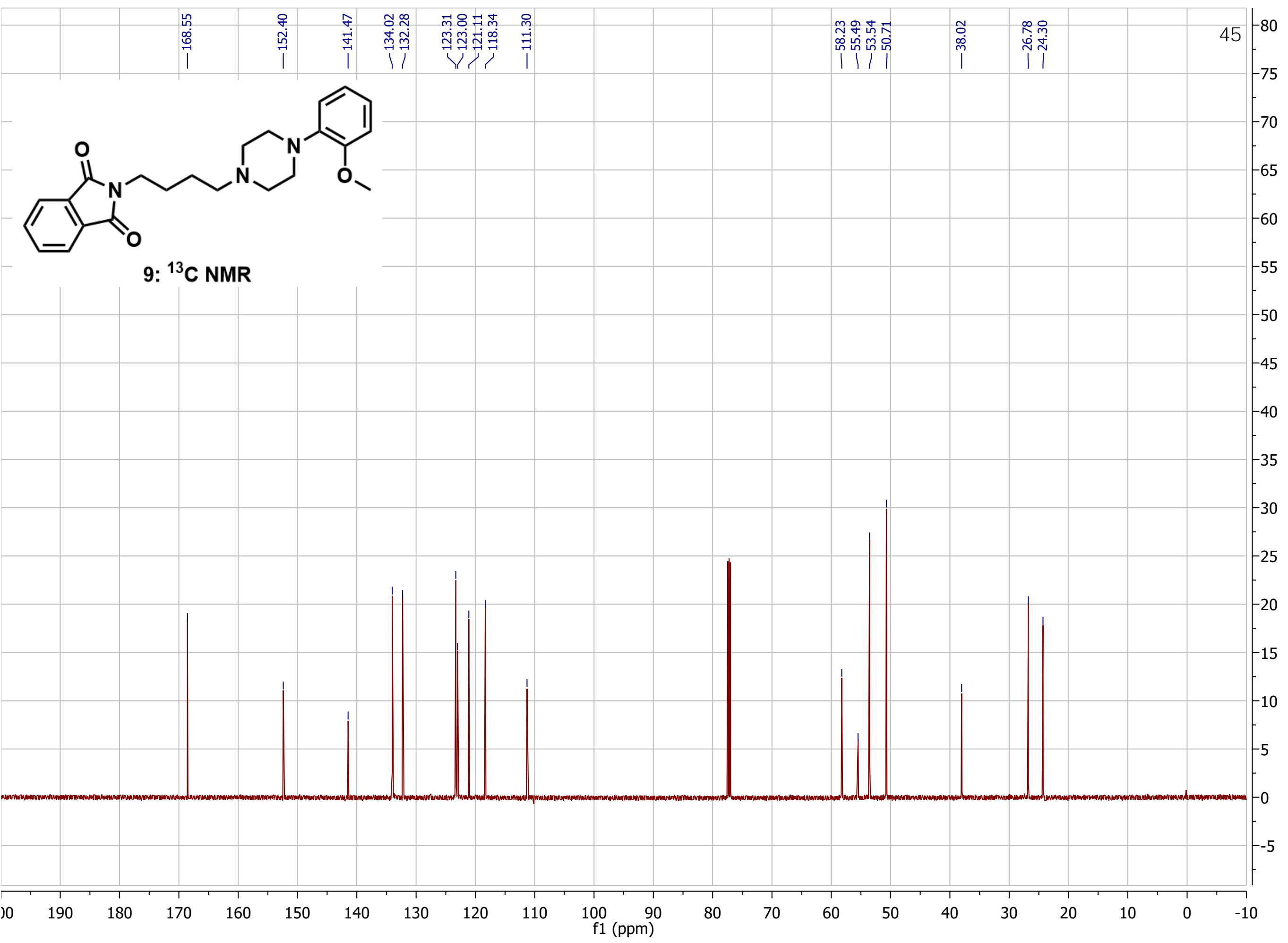




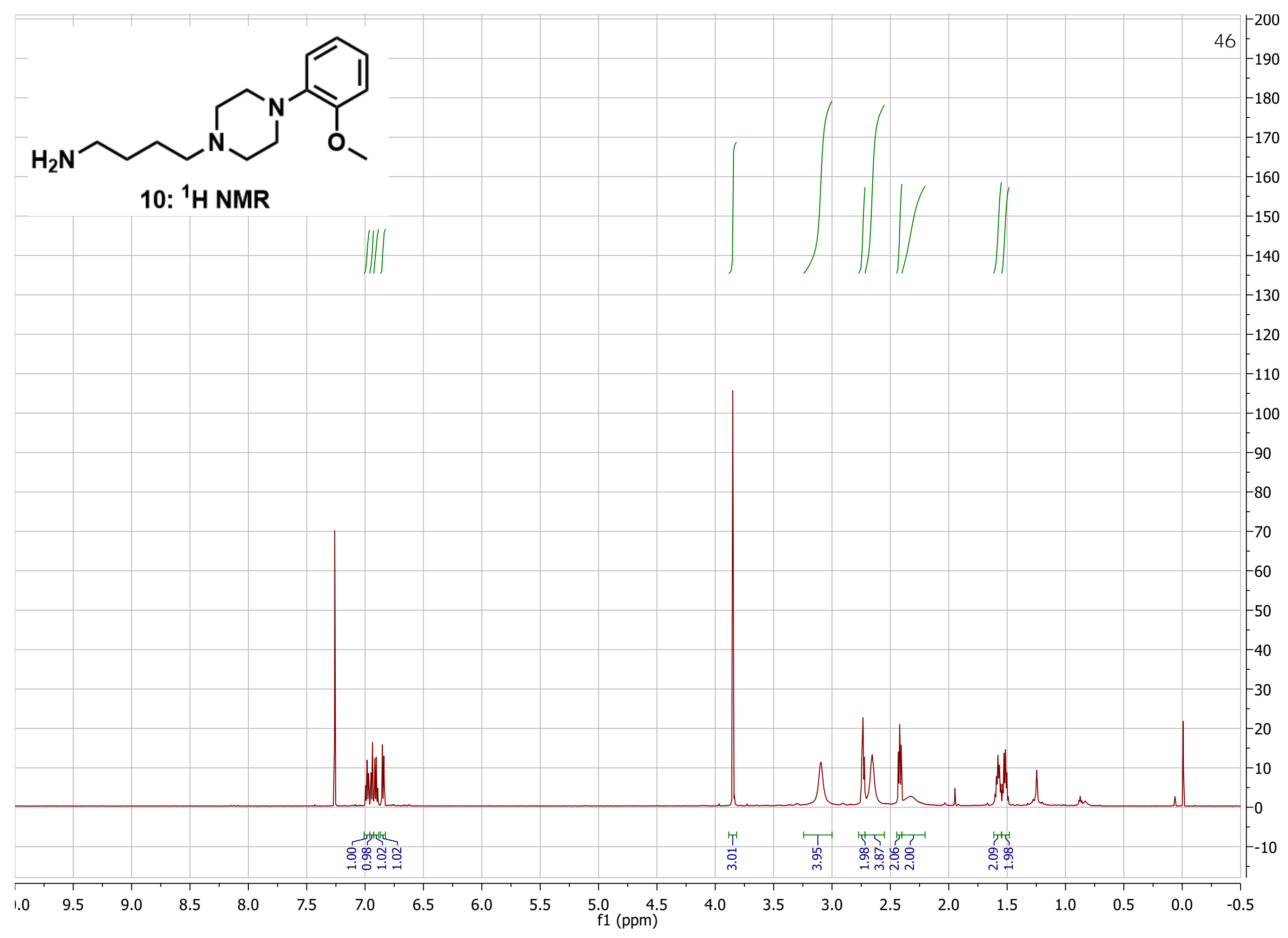




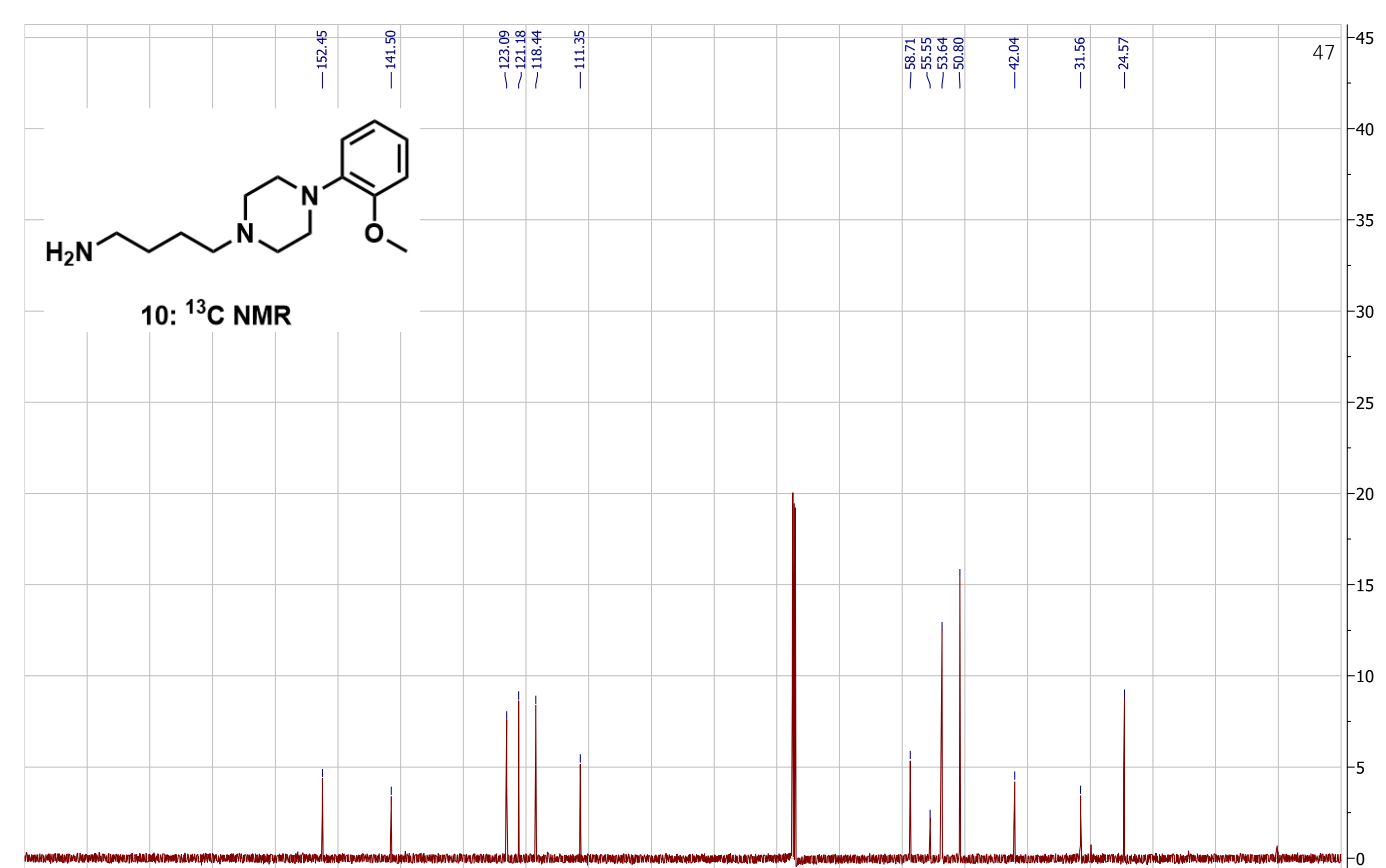




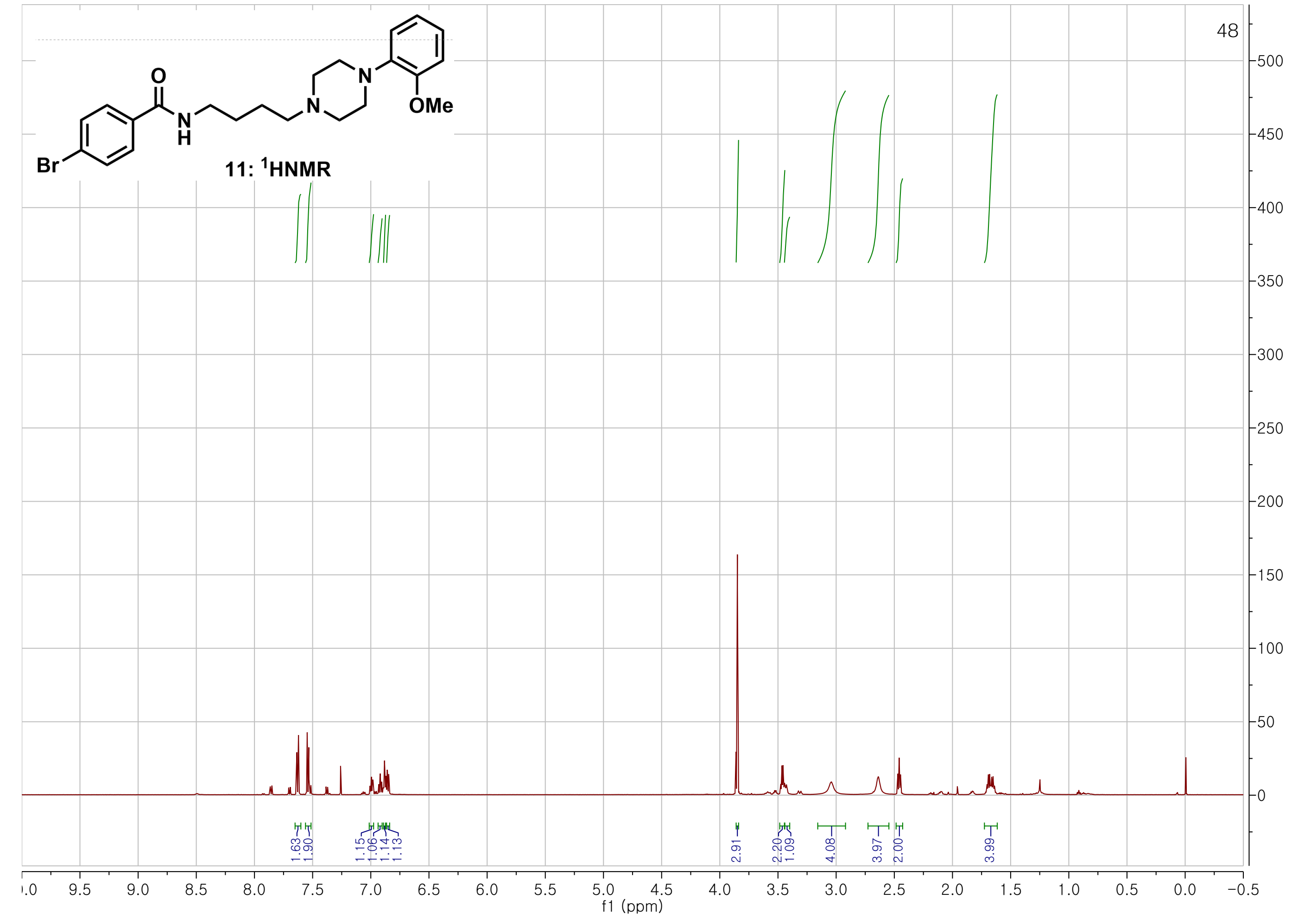

